for

\title{
Gold-Catalyzed Cycloisomerization of Propargyl Pyruvates Enabling Unified Access to Tricladolides C-D, Chaetomellic Anhydride A and Tyromycin A
}

Pathan Mosim Amin, Zhenjie Su, Shaozhong Wang*

State Key Laboratory of Coordination Chemistry, Jiangsu Key Laboratory of Advanced Organic Materials, School of Chemistry and Chemical Engineering, Nanjing University, Nanjing 210023, China.

Email: wangsz@nju.edu.cn

Table of Contents

1. ${ }^{1} \mathrm{H}$ and ${ }^{13} \mathrm{C}$ NMR spectra for all compounds

2. NOESY spectra of compound $\mathbf{1 8}$ 
1. ${ }^{1} \mathrm{H}$ and ${ }^{13} \mathrm{C}$ NMR spectra for all compounds
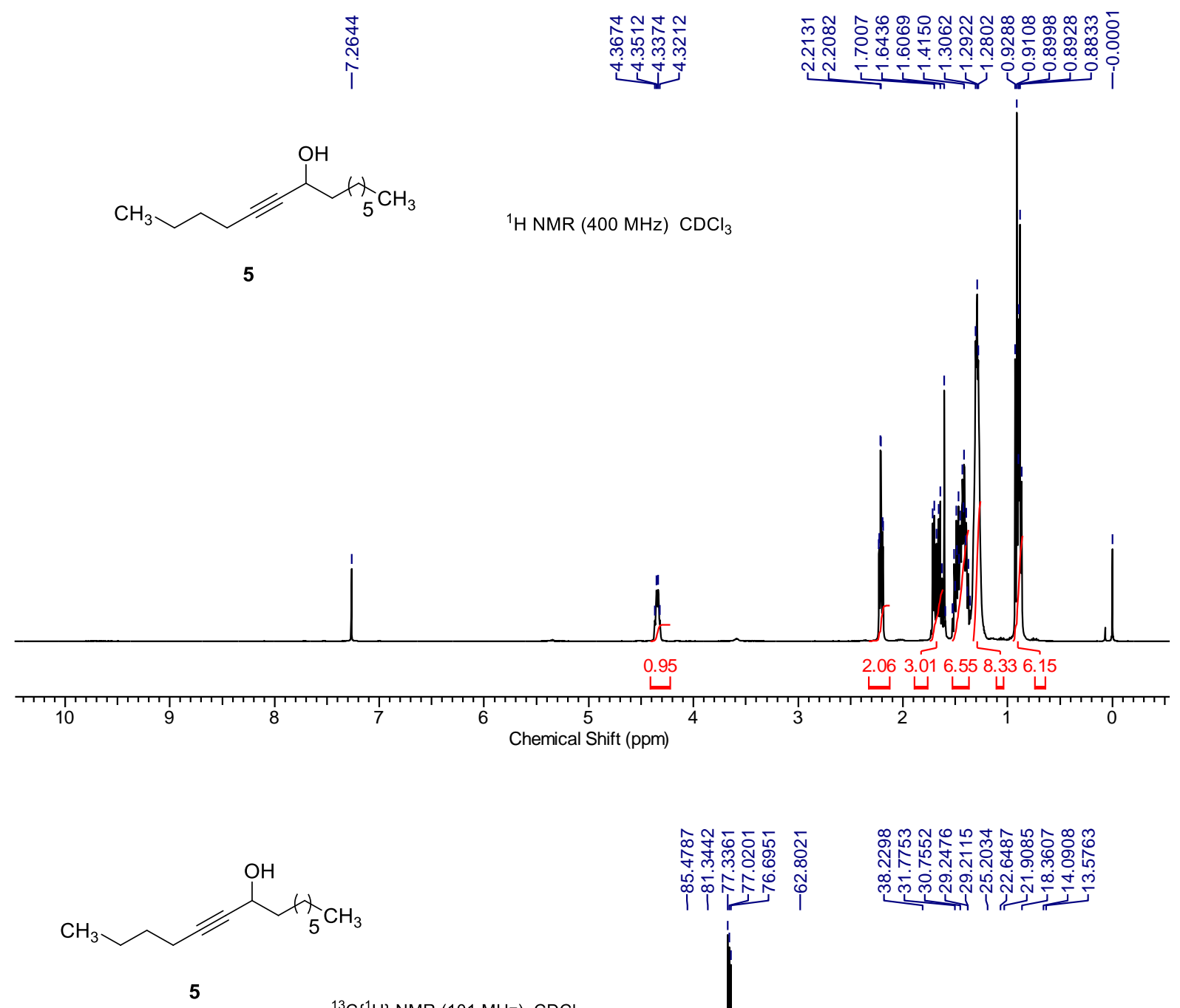

${ }^{13} \mathrm{C}\left\{{ }^{1} \mathrm{H}\right\}$ NMR $(101 \mathrm{MHz}) \mathrm{CDCl}_{3}$

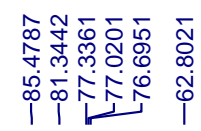

赵

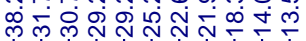

11

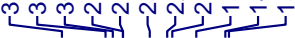

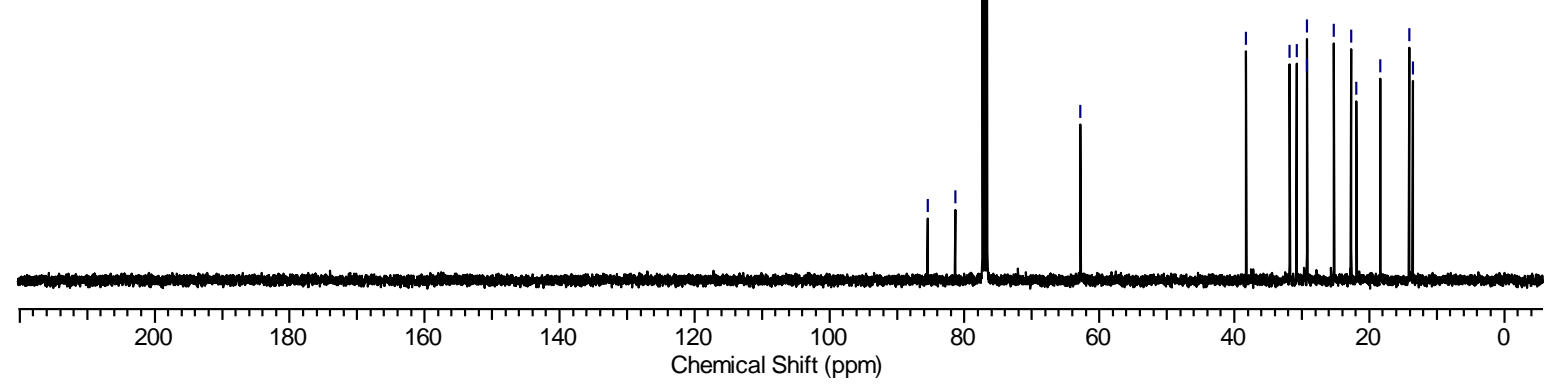



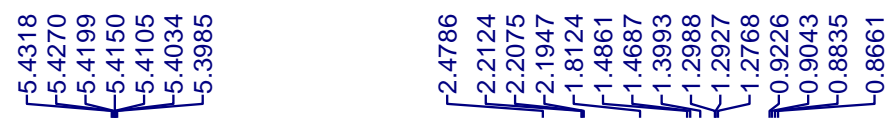

${ }^{1} \mathrm{H}$ NMR (400 MHz) $\mathrm{CDCl}_{3}$

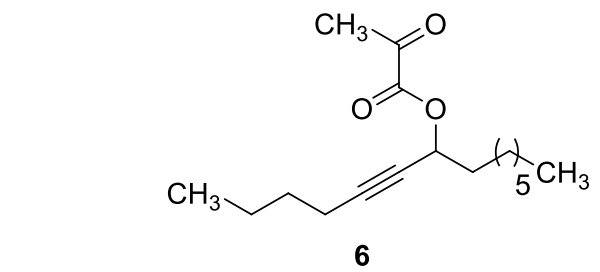

6

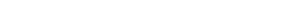
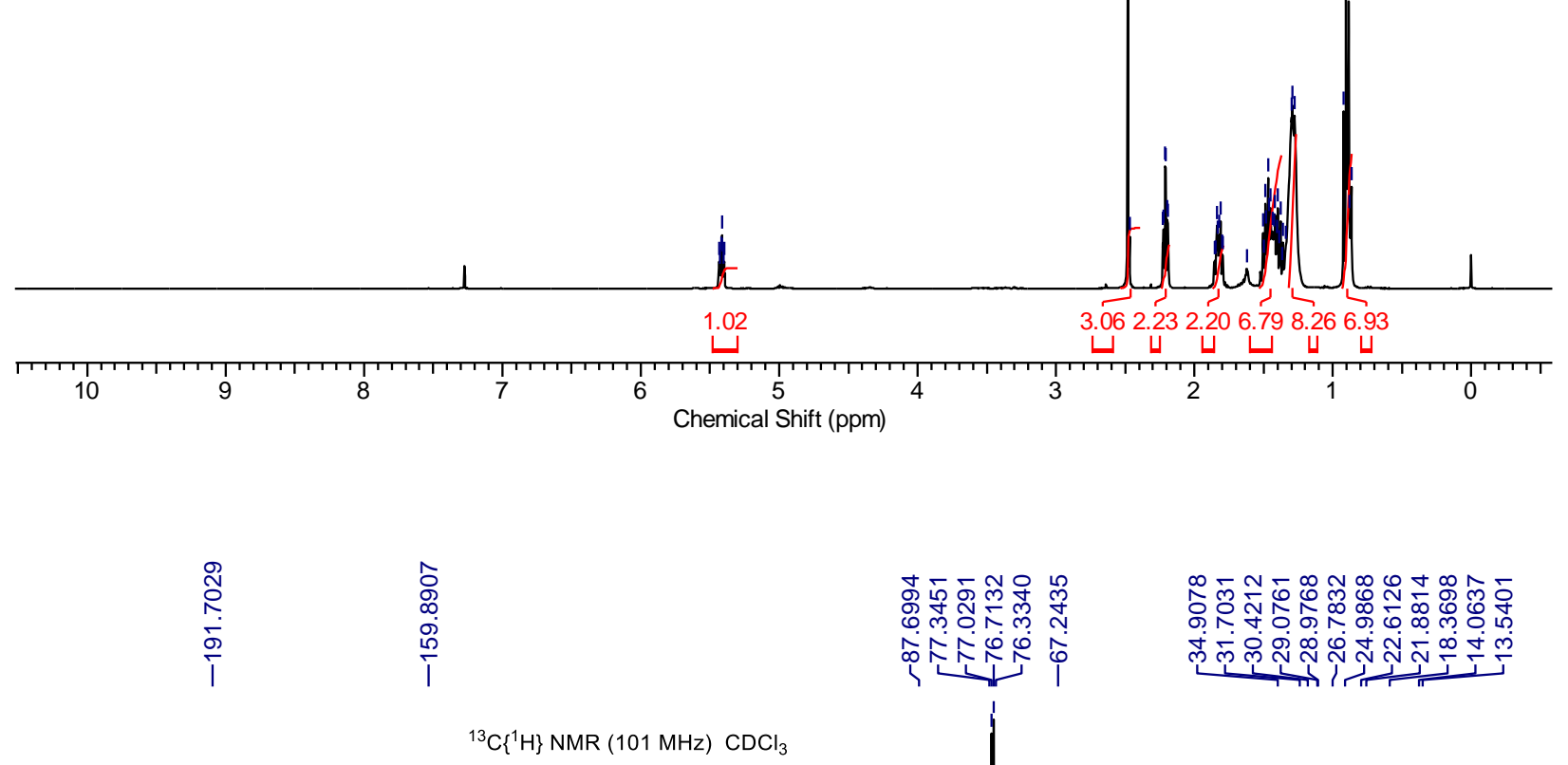

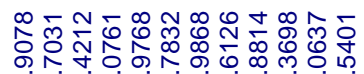

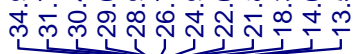
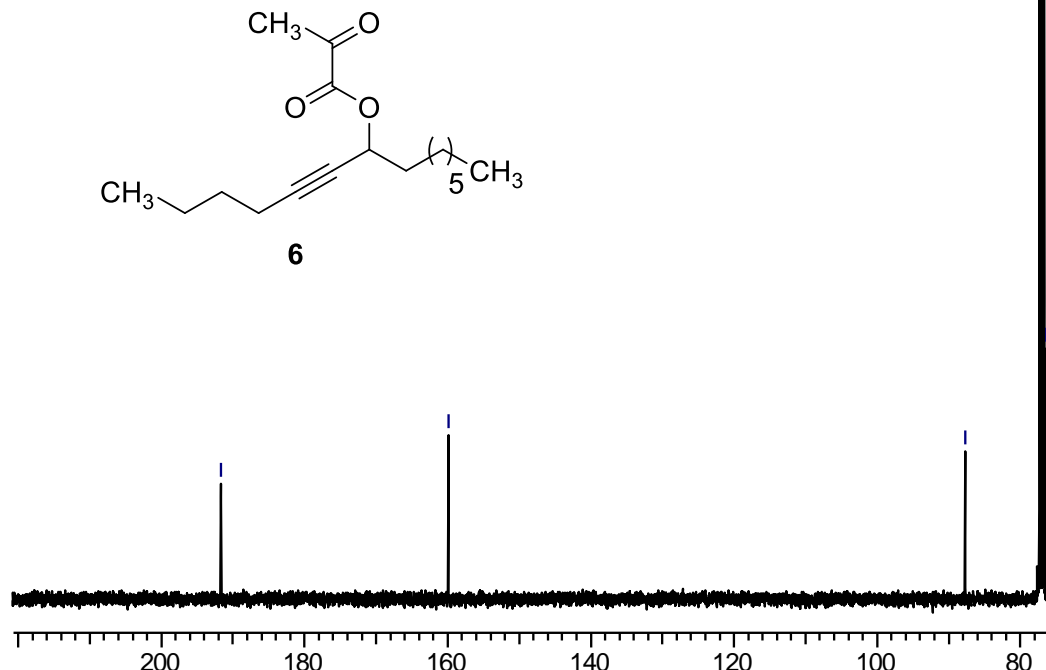

200

180

160

140

120

100

80

60

40

20 


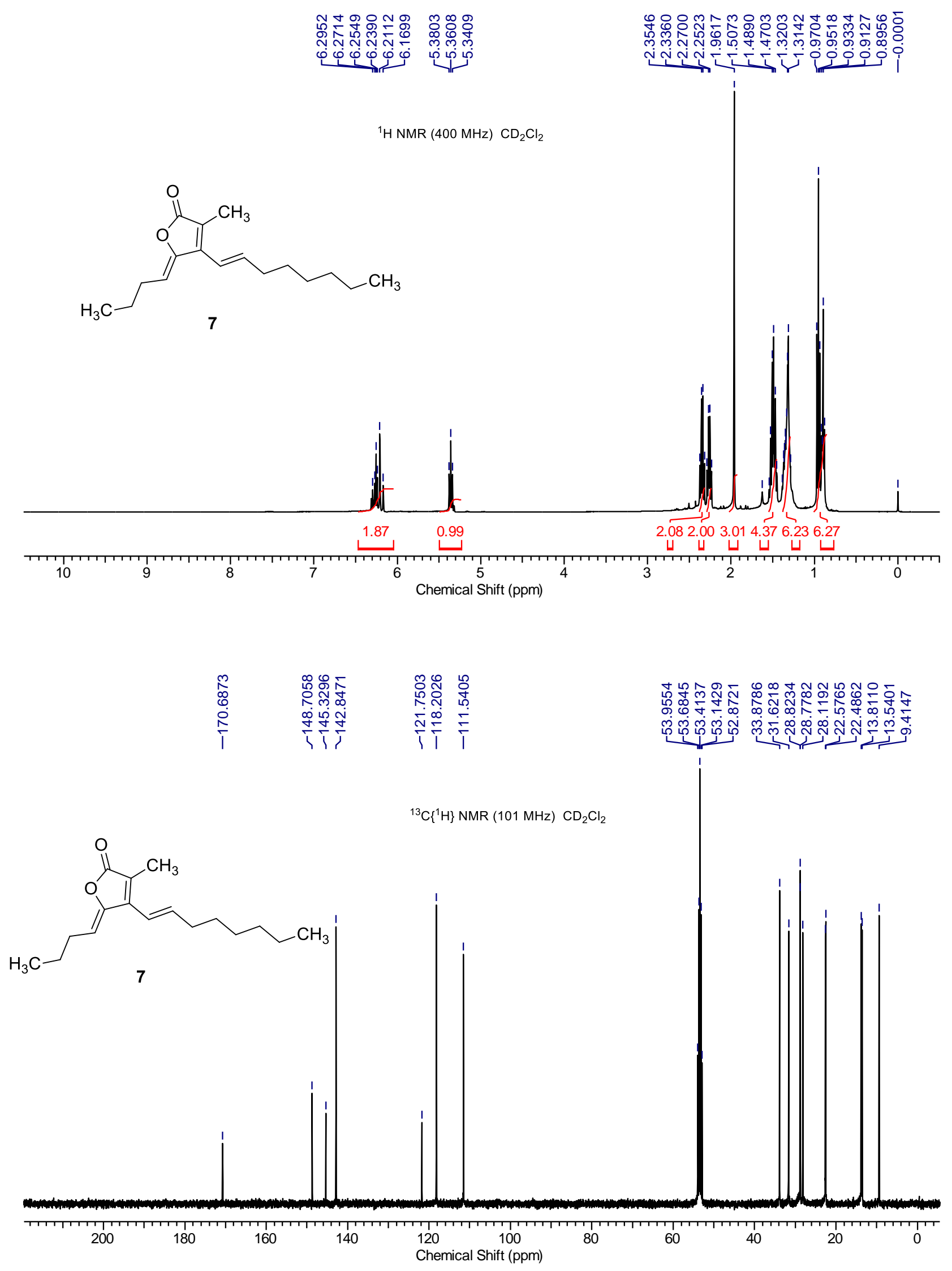




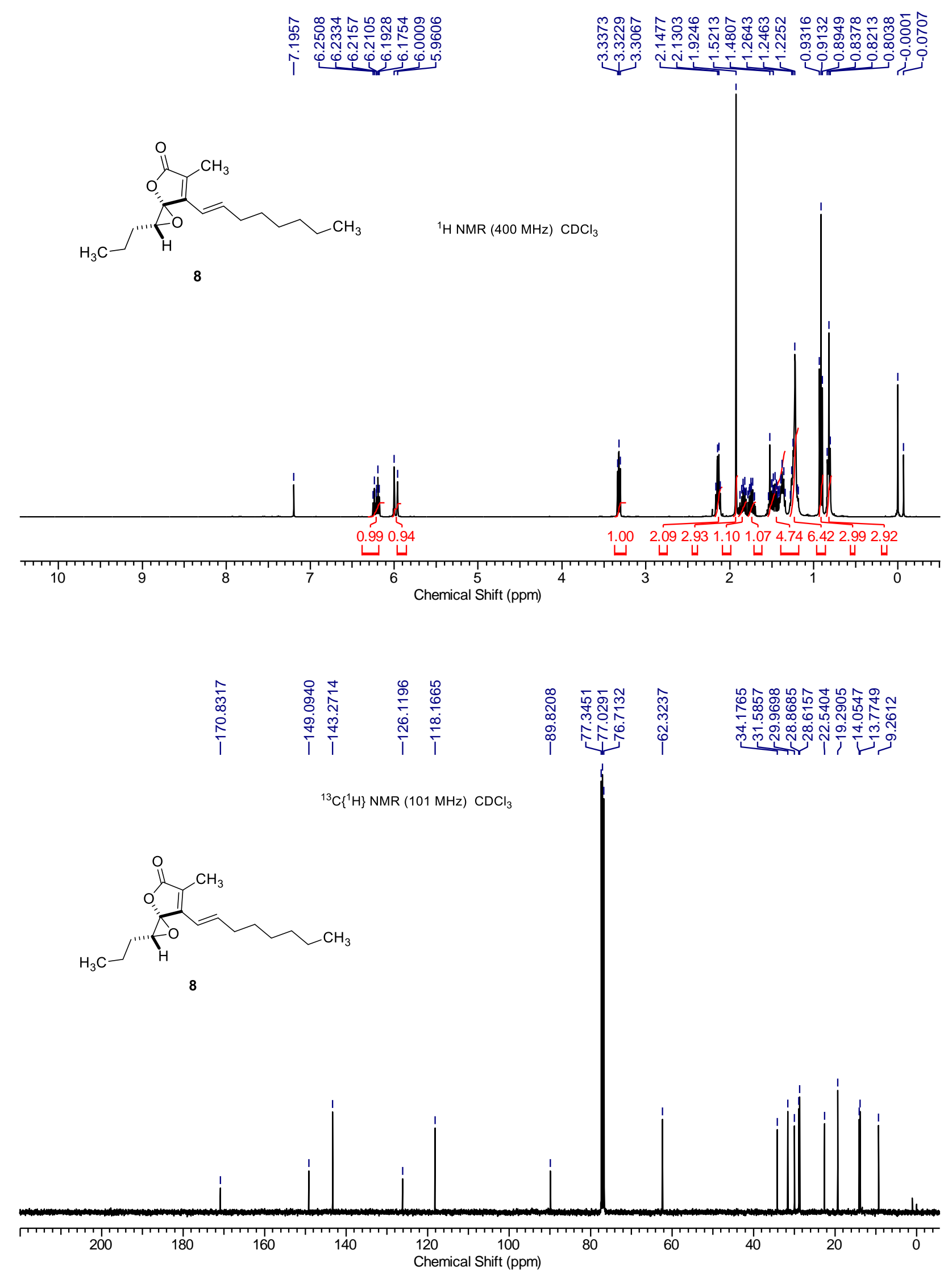




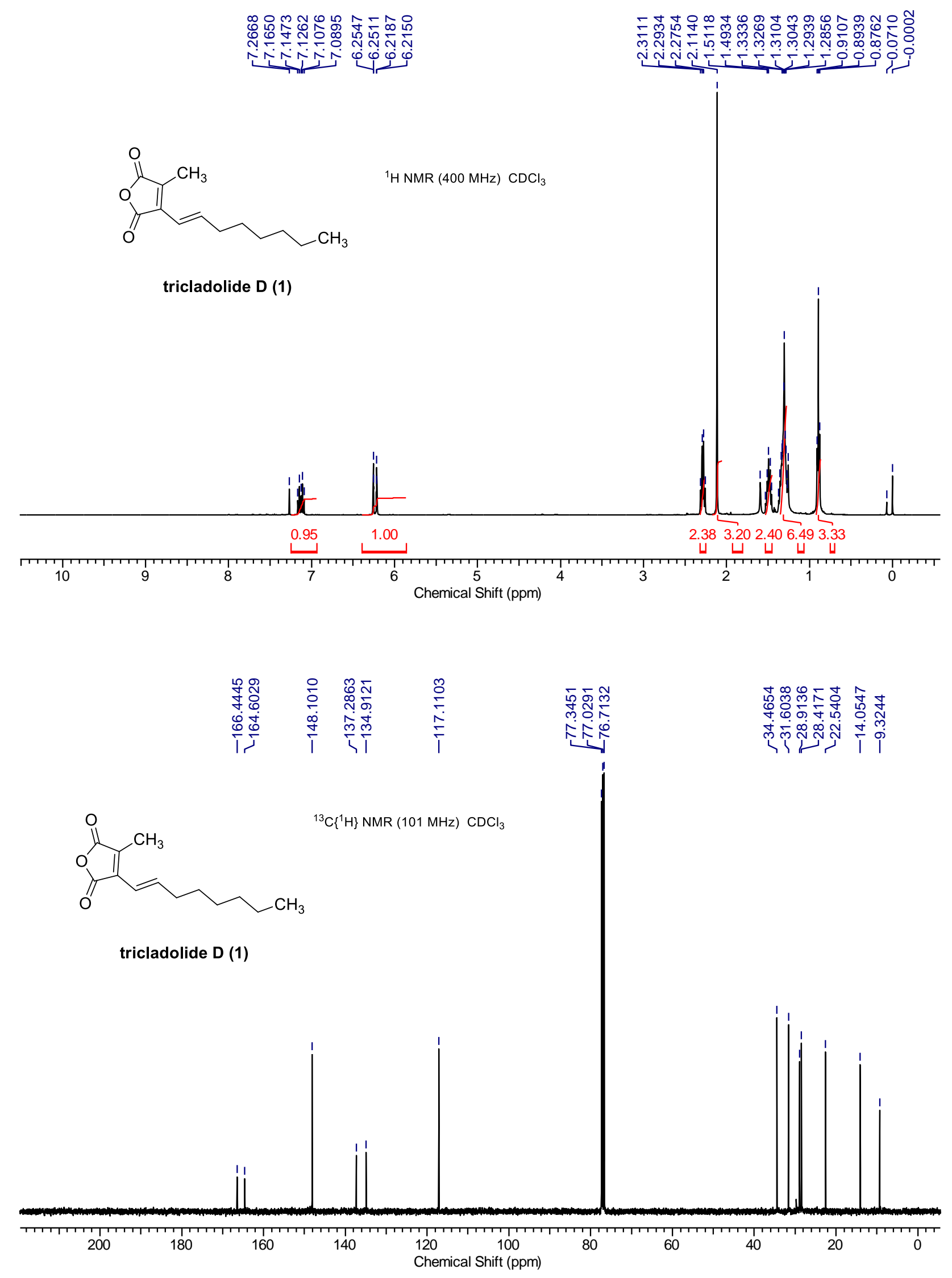



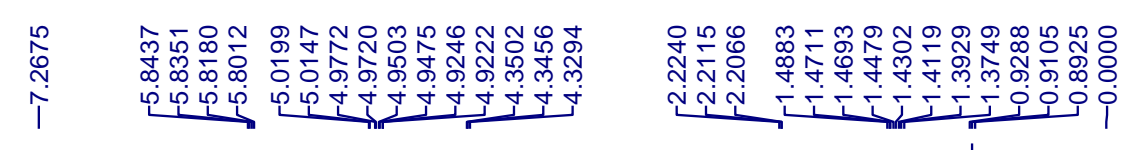

${ }^{1} \mathrm{H}$ NMR $(400 \mathrm{MHz}) \mathrm{CDCl}_{3}$

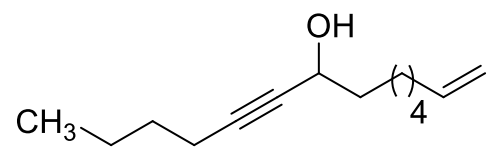

9
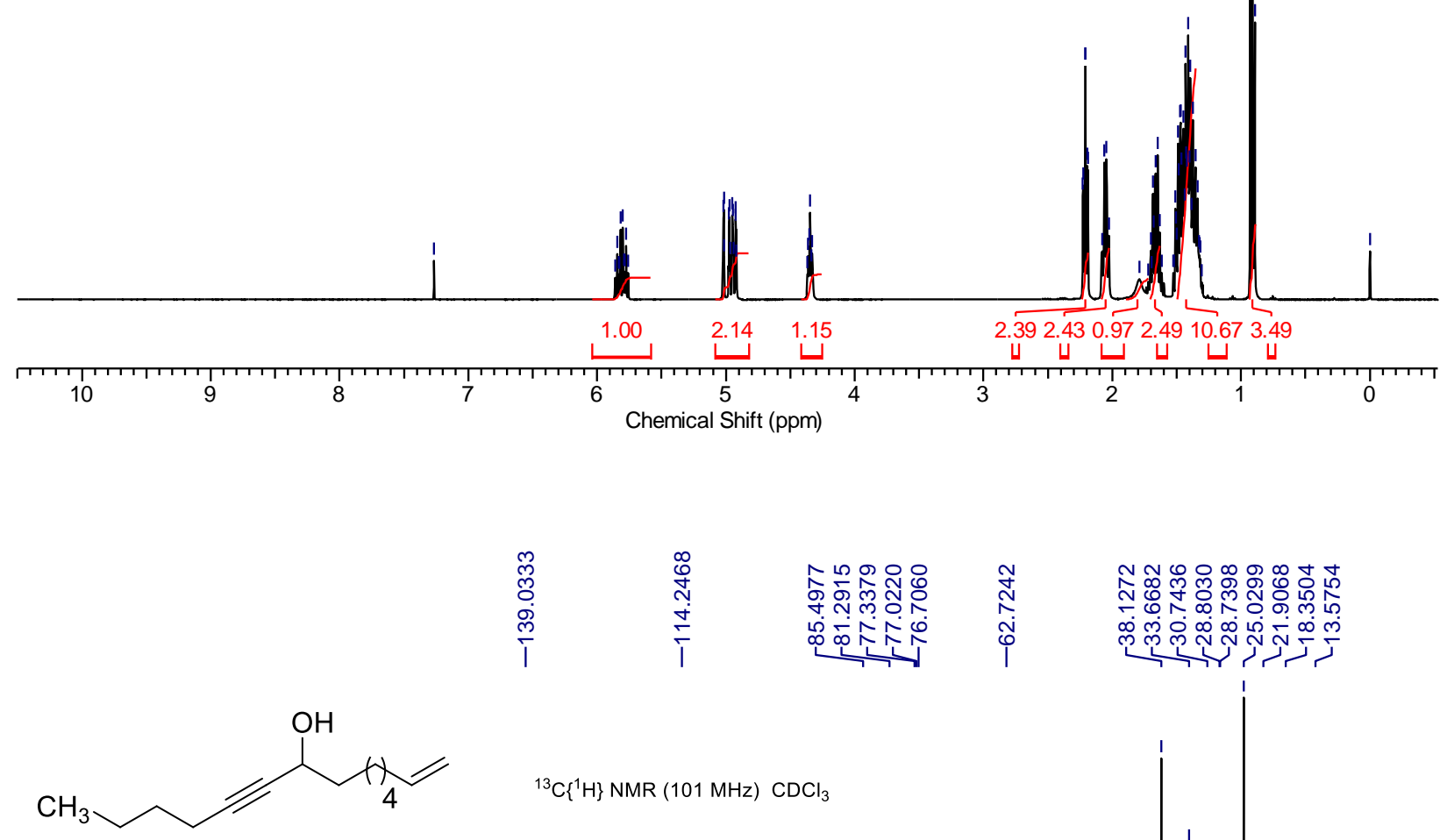

${ }^{13} \mathrm{C}\left\{{ }^{1} \mathrm{H}\right\}$ NMR $(101 \mathrm{MHz}) \mathrm{CDCl}_{3}$

9

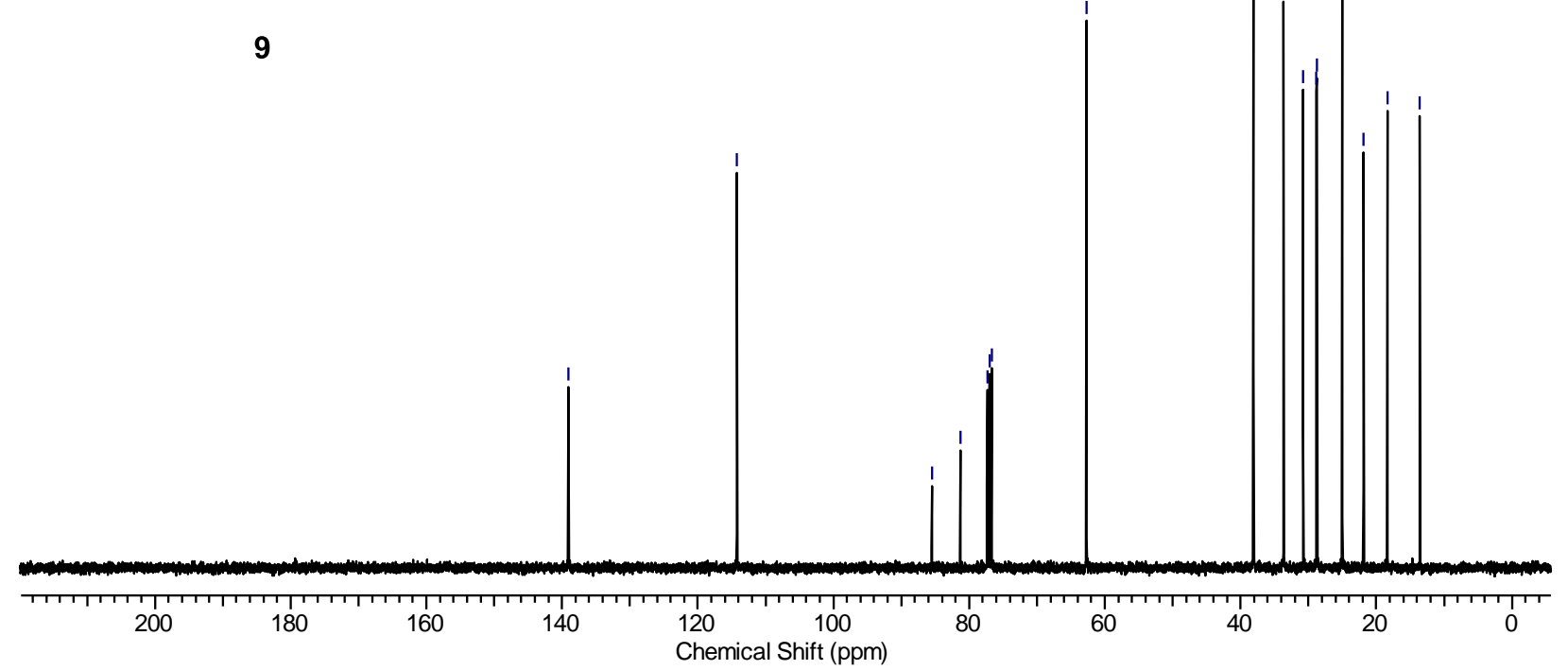




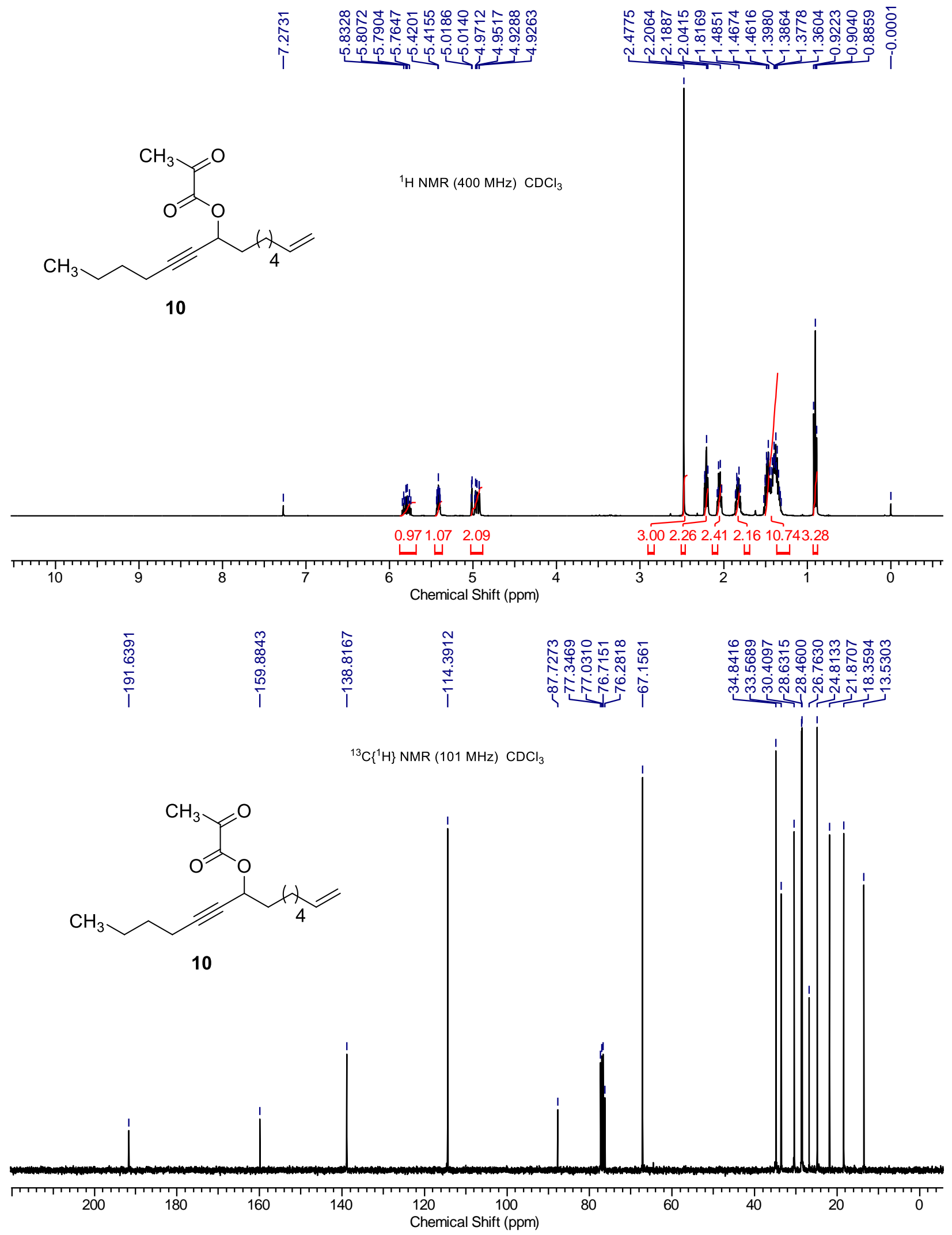




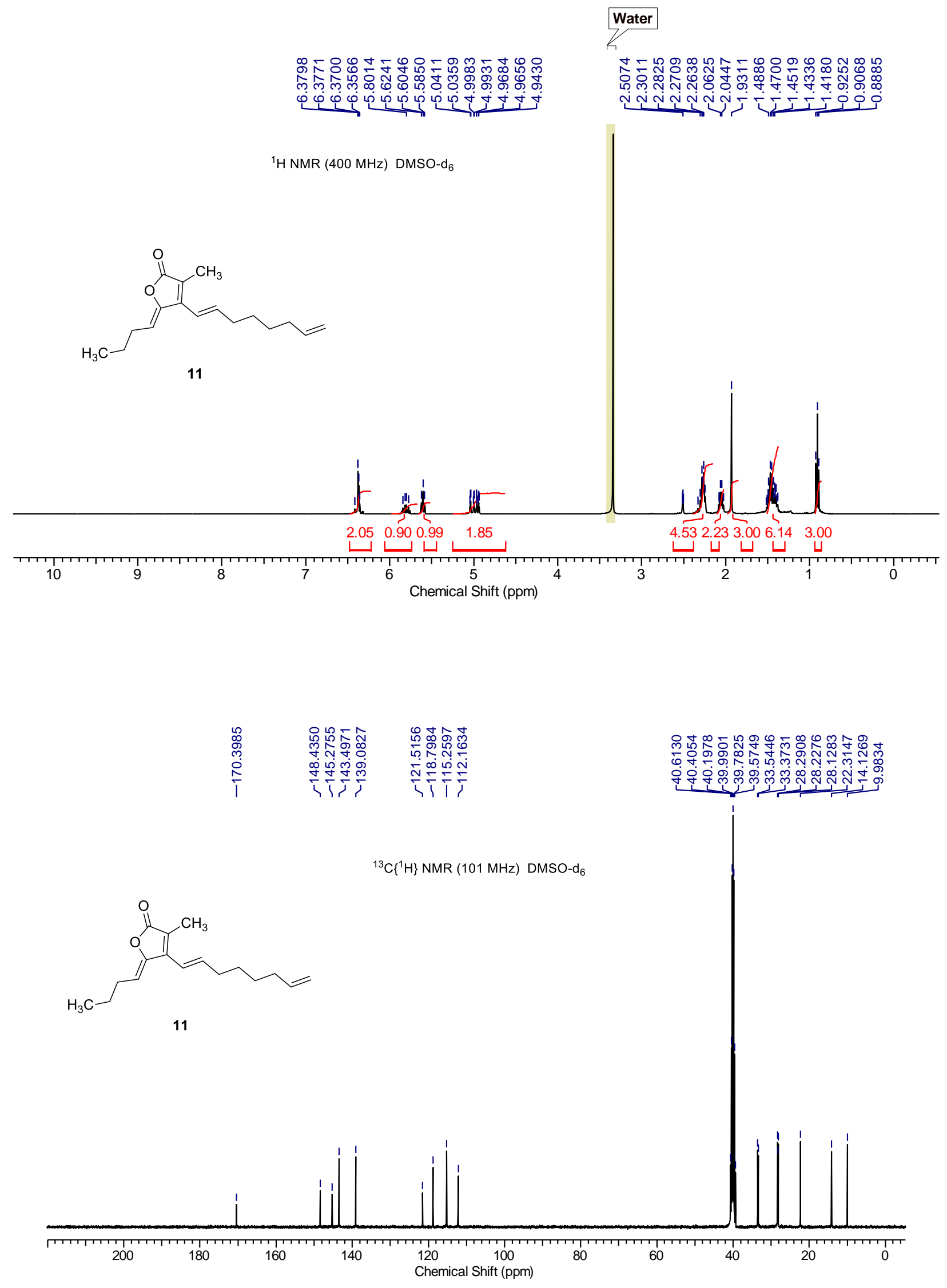




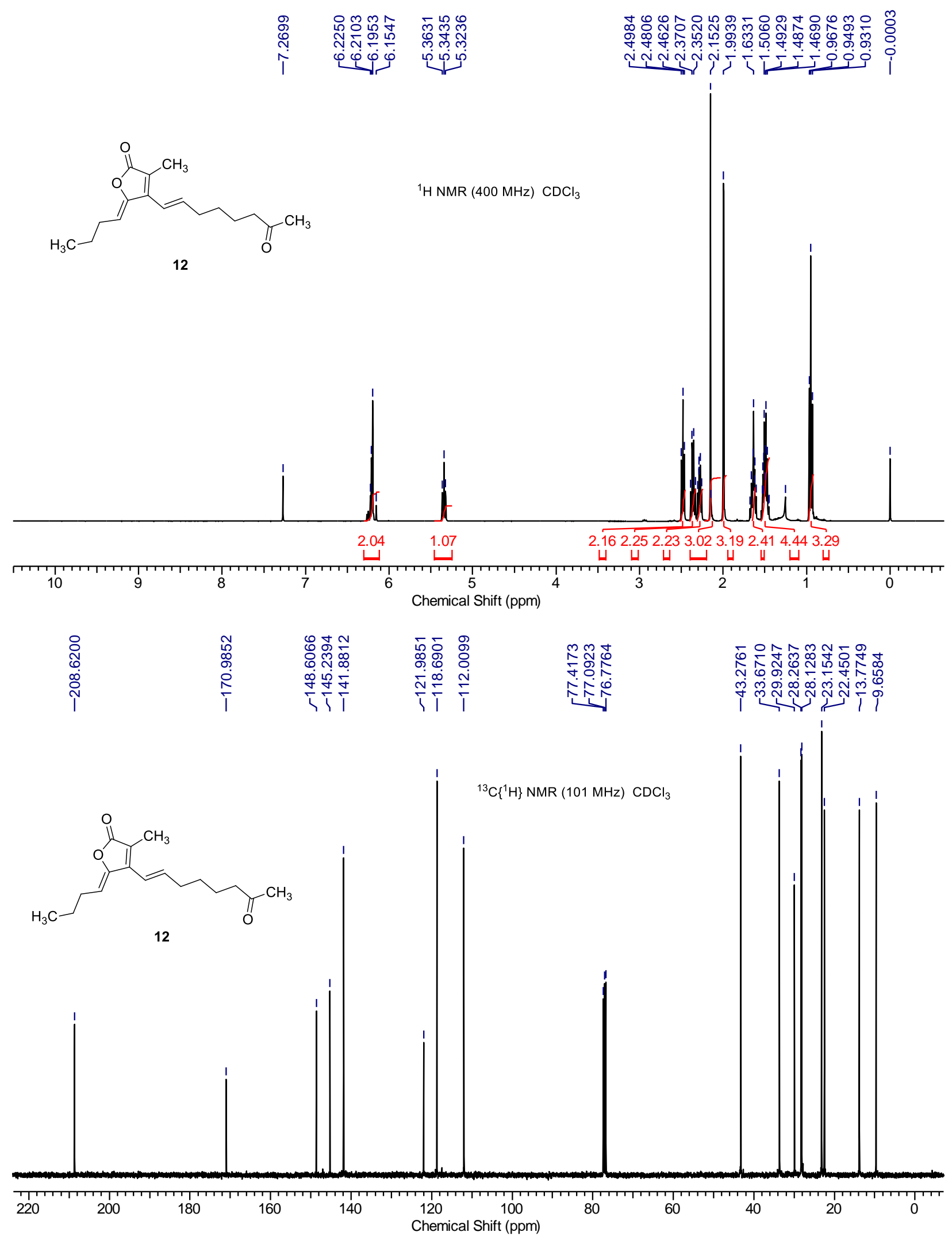



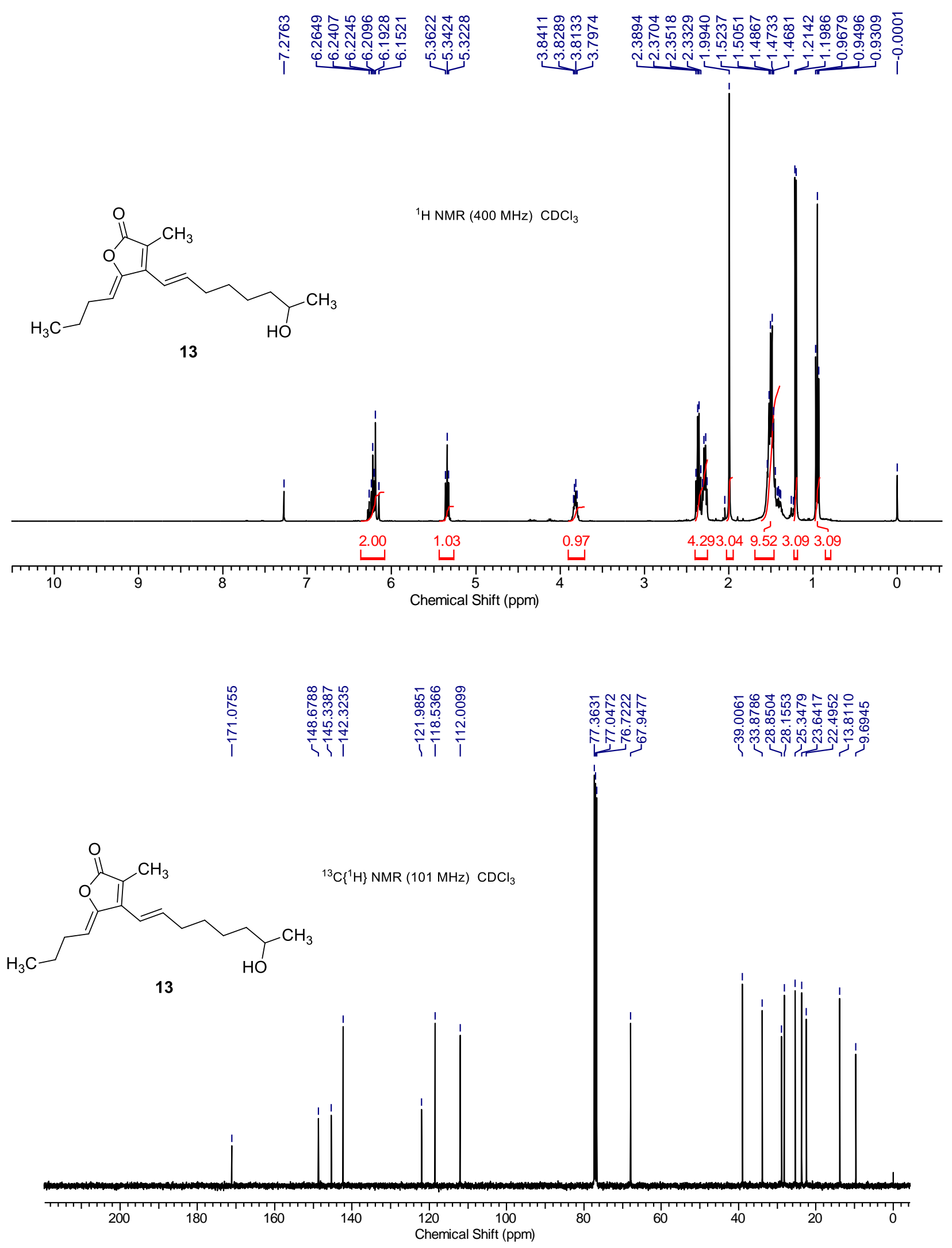
${ }^{1} \mathrm{H} \mathrm{NMR}(400 \mathrm{MHz}) \mathrm{CDCl}_{3}$

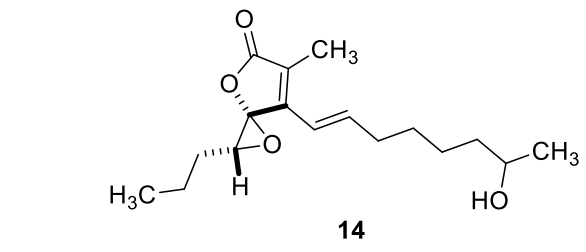

14

(

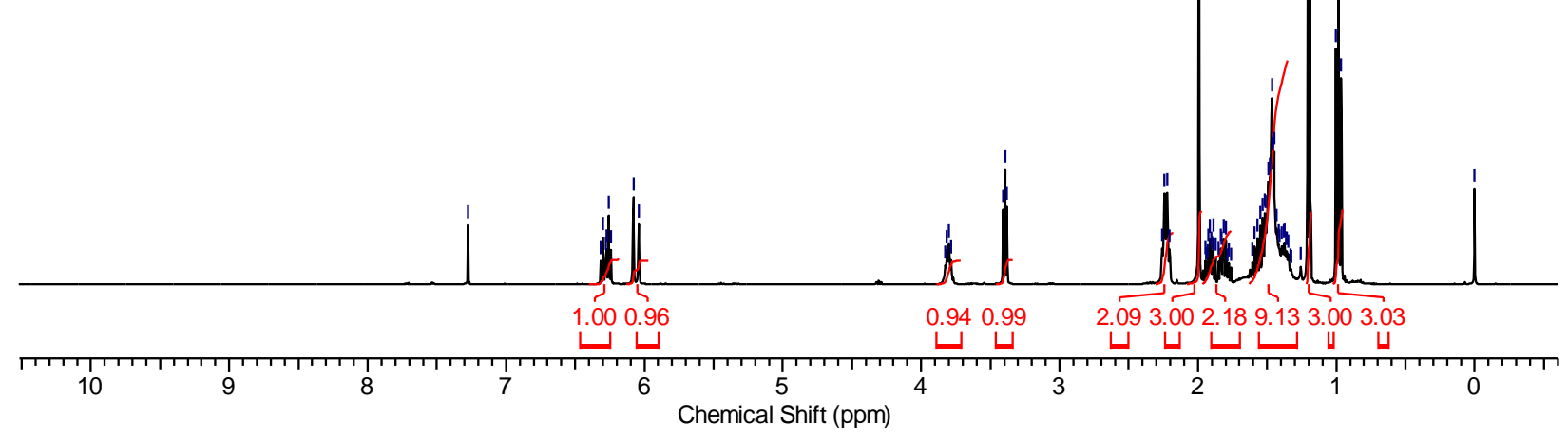

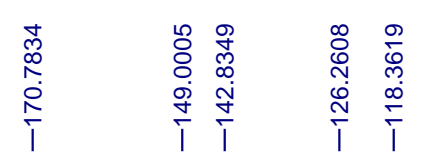

${ }^{13} \mathrm{C}\left\{{ }^{1} \mathrm{H}\right\}$ NMR (101 MHz) CDCl${ }_{3}$

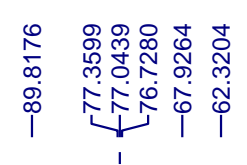

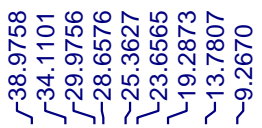<smiles>CCC[C@H]1O[C@]12OC(=O)C(C)=C2/C=C/CCCCC(C)O</smiles>

14

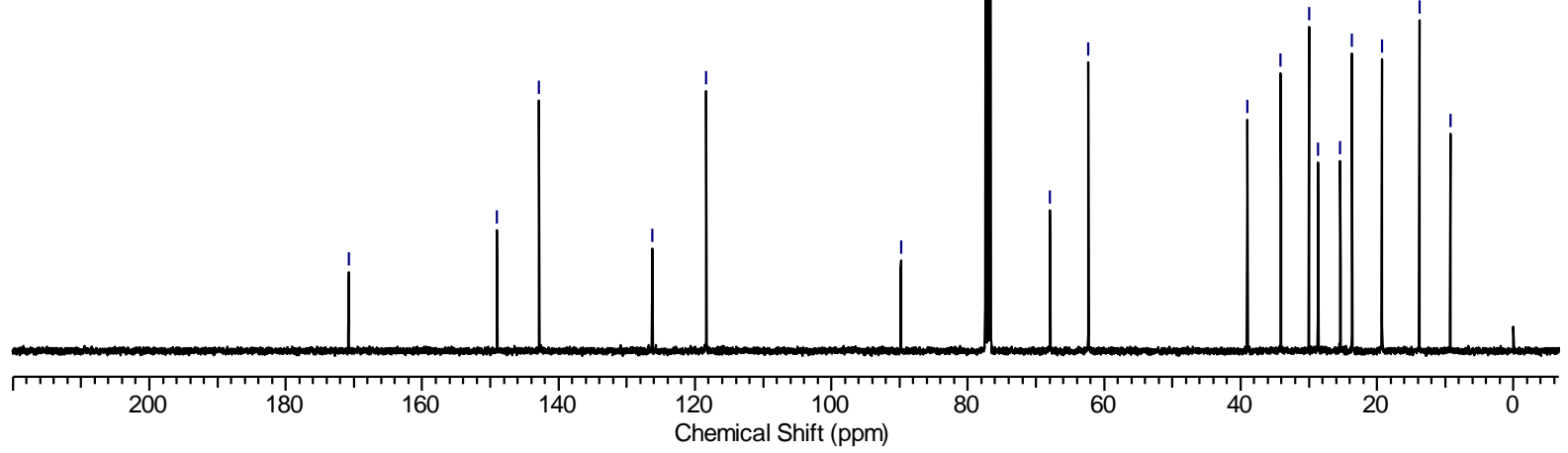



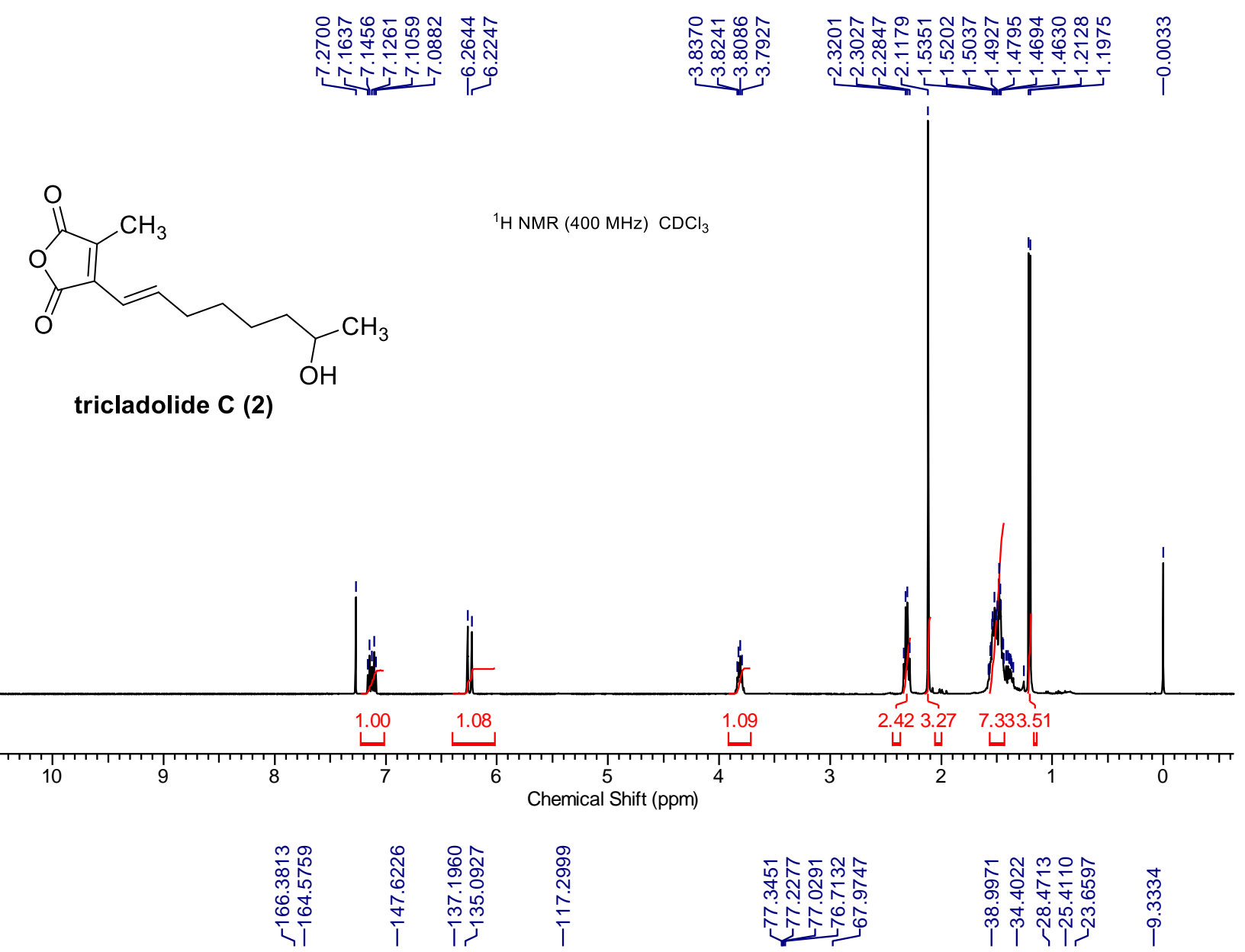

${ }^{13} \mathrm{C}\left\{{ }^{1} \mathrm{H}\right\}$ NMR (101 MHz) $\mathrm{CDCl}_{3}$<smiles>CC1=C(/C=C/CCCCC(C)O)C(=O)OC1=O</smiles>

tricladolide C (2)

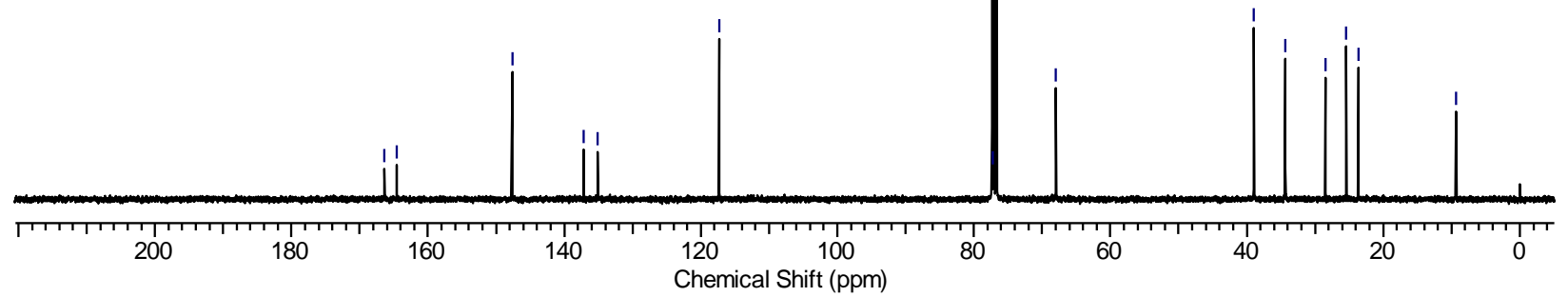



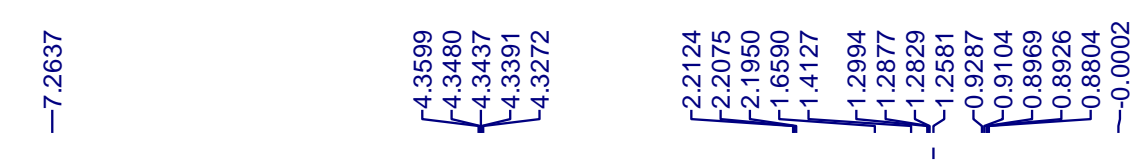

${ }^{1} \mathrm{H}$ NMR (400 MHz) $\mathrm{CDCl}_{3}$

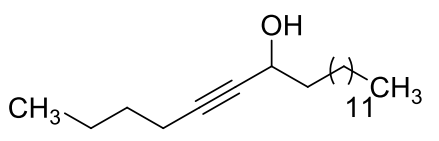

15

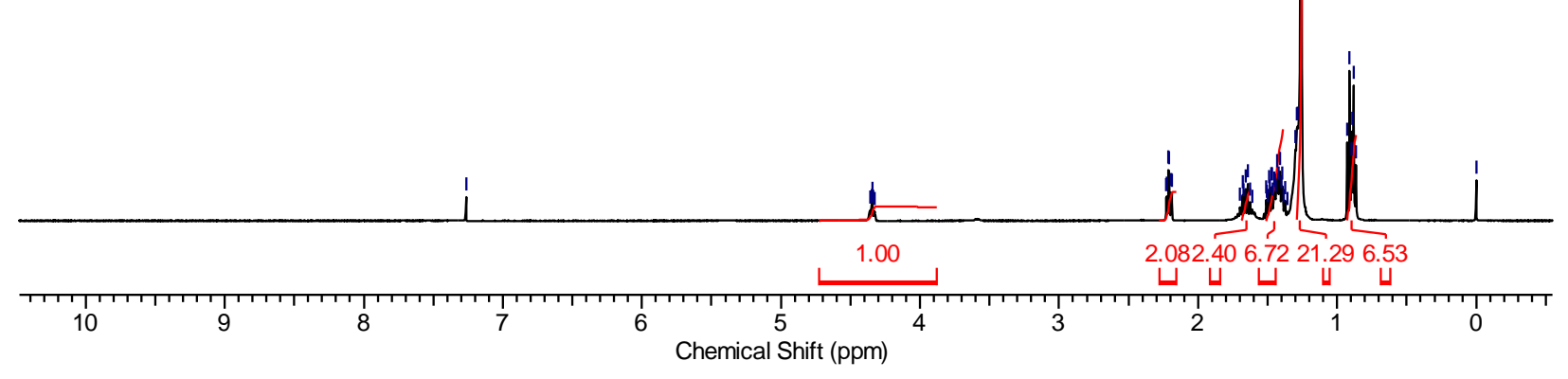

${ }^{13} \mathrm{C}\left\{{ }^{1} \mathrm{H}\right\}$ NMR $(101 \mathrm{MHz}) \mathrm{CDCl}_{3}$
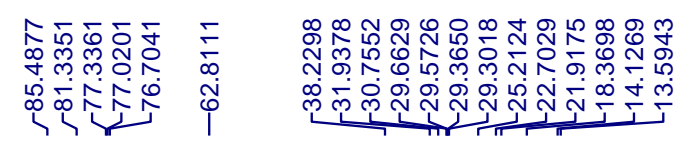

๓

पर

J

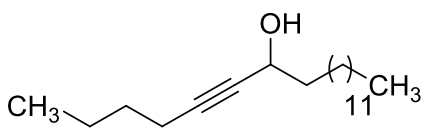

15

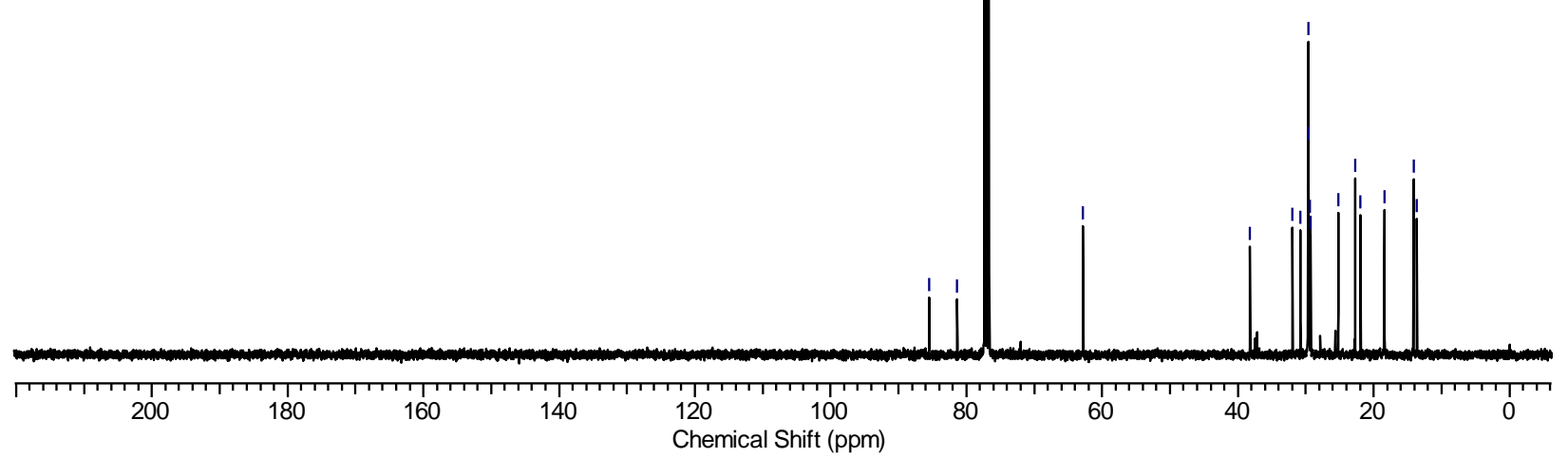




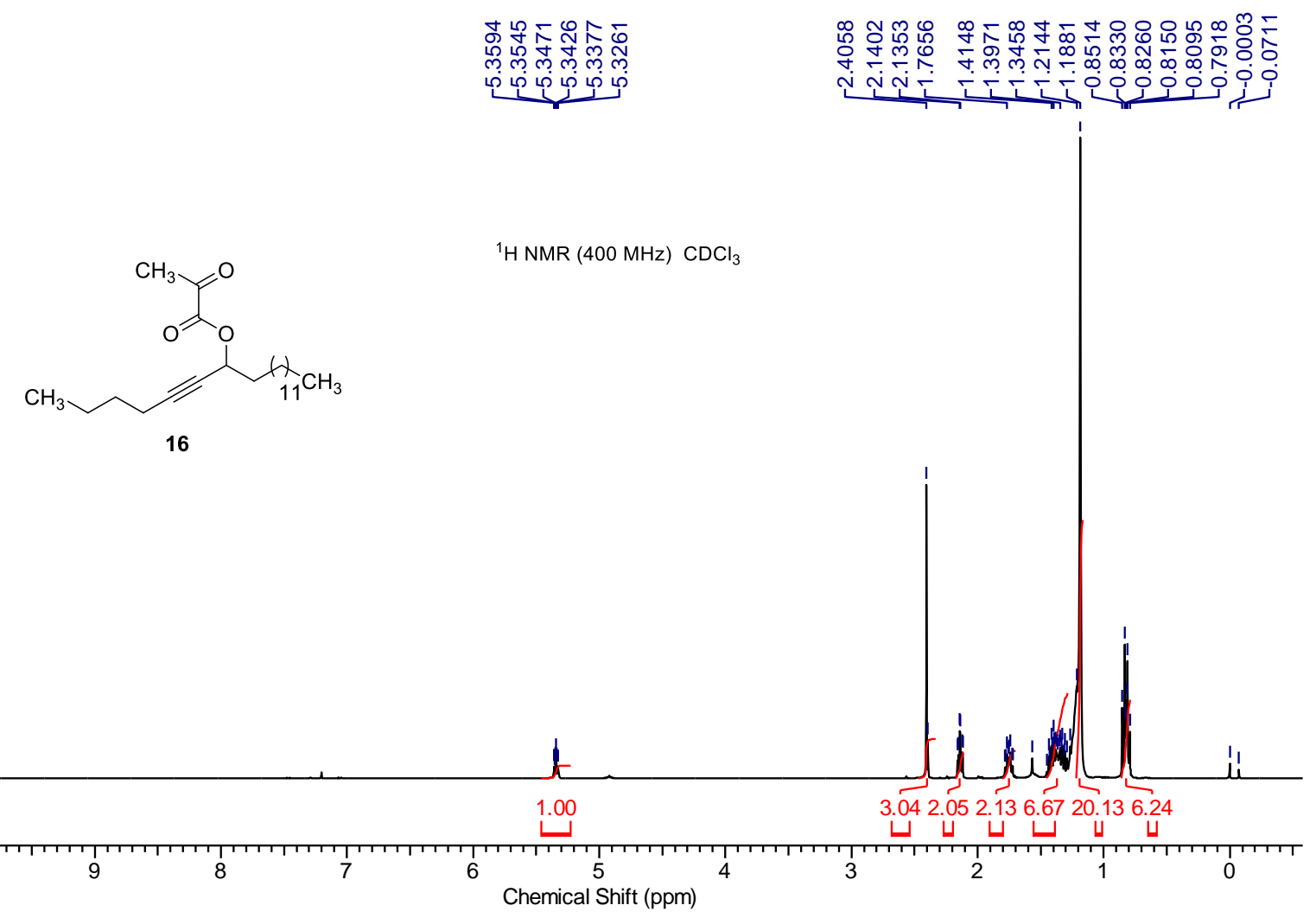

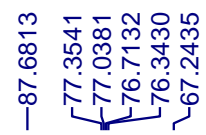

${ }^{13} \mathrm{C}\left\{{ }^{1} \mathrm{H}\right\}$ NMR $(101 \mathrm{MHz}) \mathrm{CDCl}_{3}$

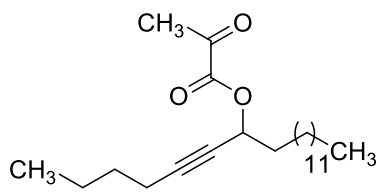

16

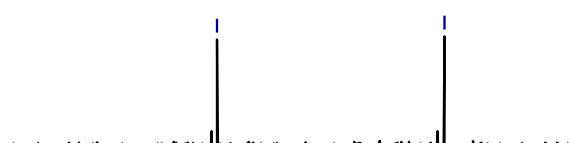

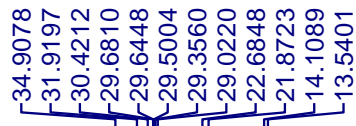

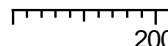

200

180

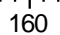

140

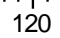

Chemical Shift (ppm)

11
80

60

0

40

40

20

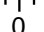




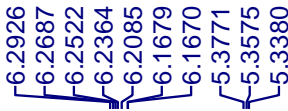

${ }^{1} \mathrm{H}$ NMR (400 MHz) $\mathrm{CD}_{2} \mathrm{Cl}_{2}$

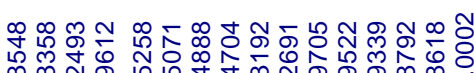

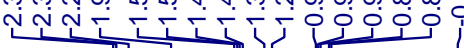
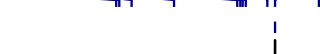
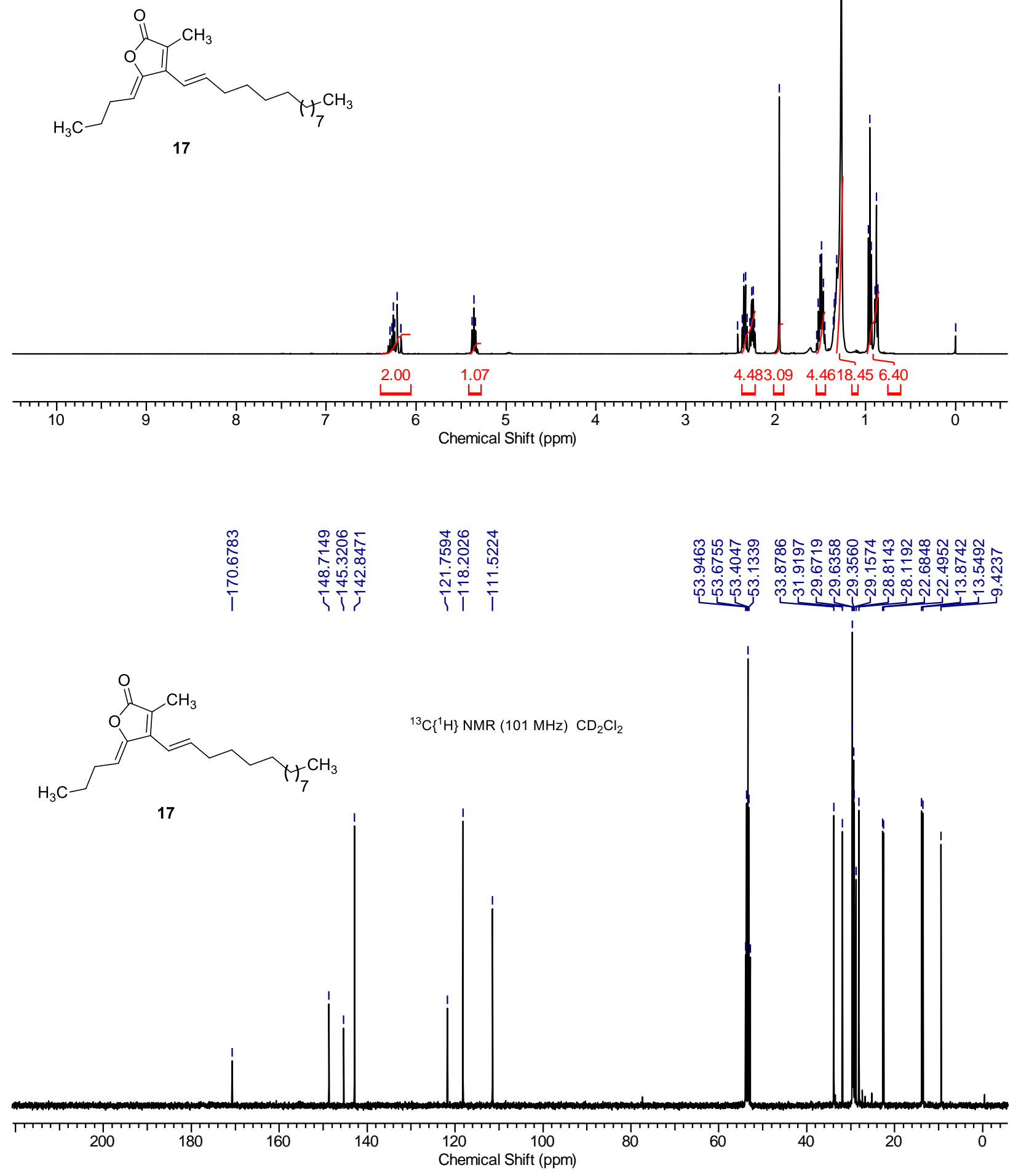


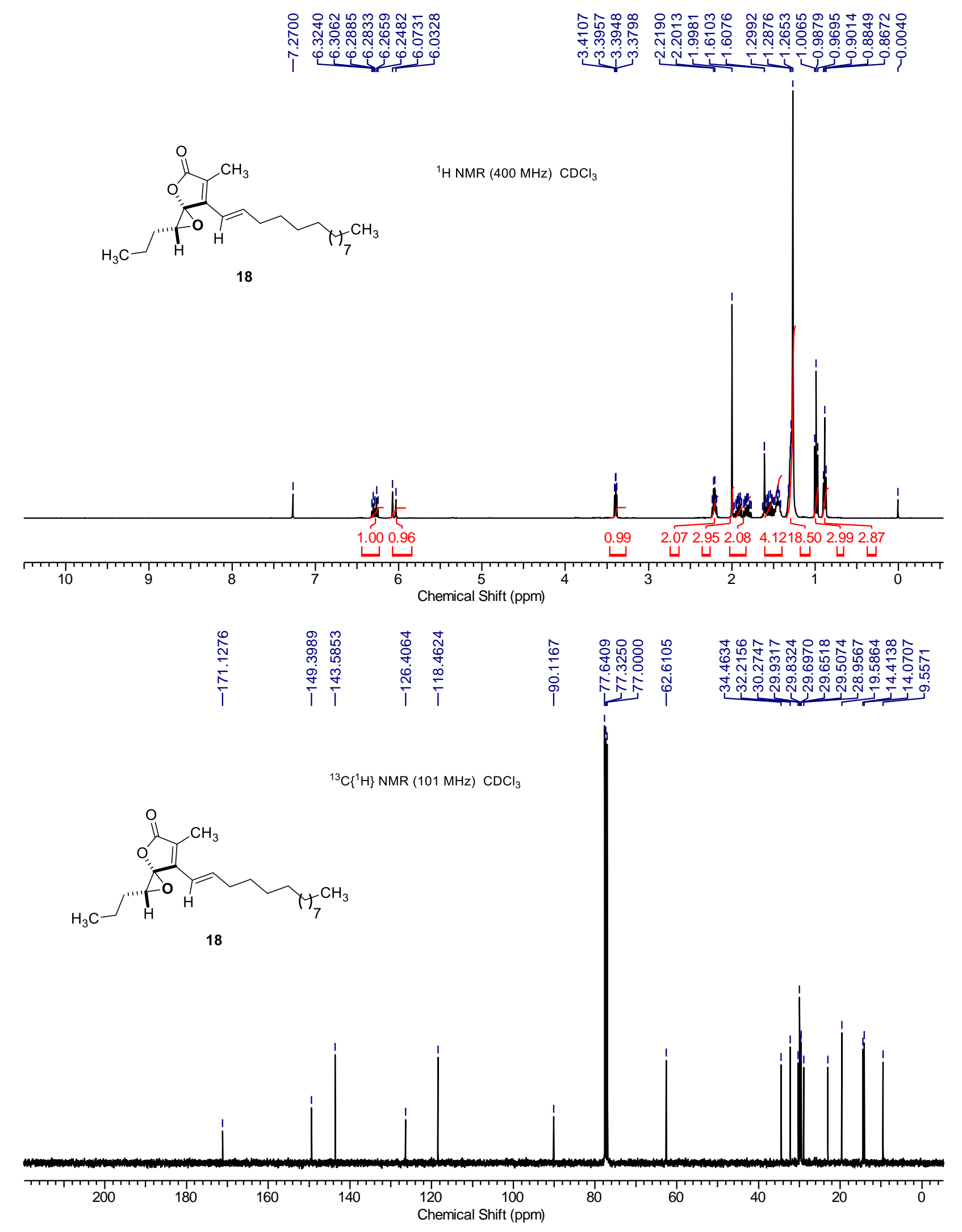


${ }^{1} \mathrm{H} \mathrm{NMR}(400 \mathrm{MHz}) \mathrm{CDCl}_{3}$

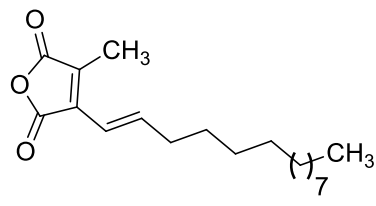

19
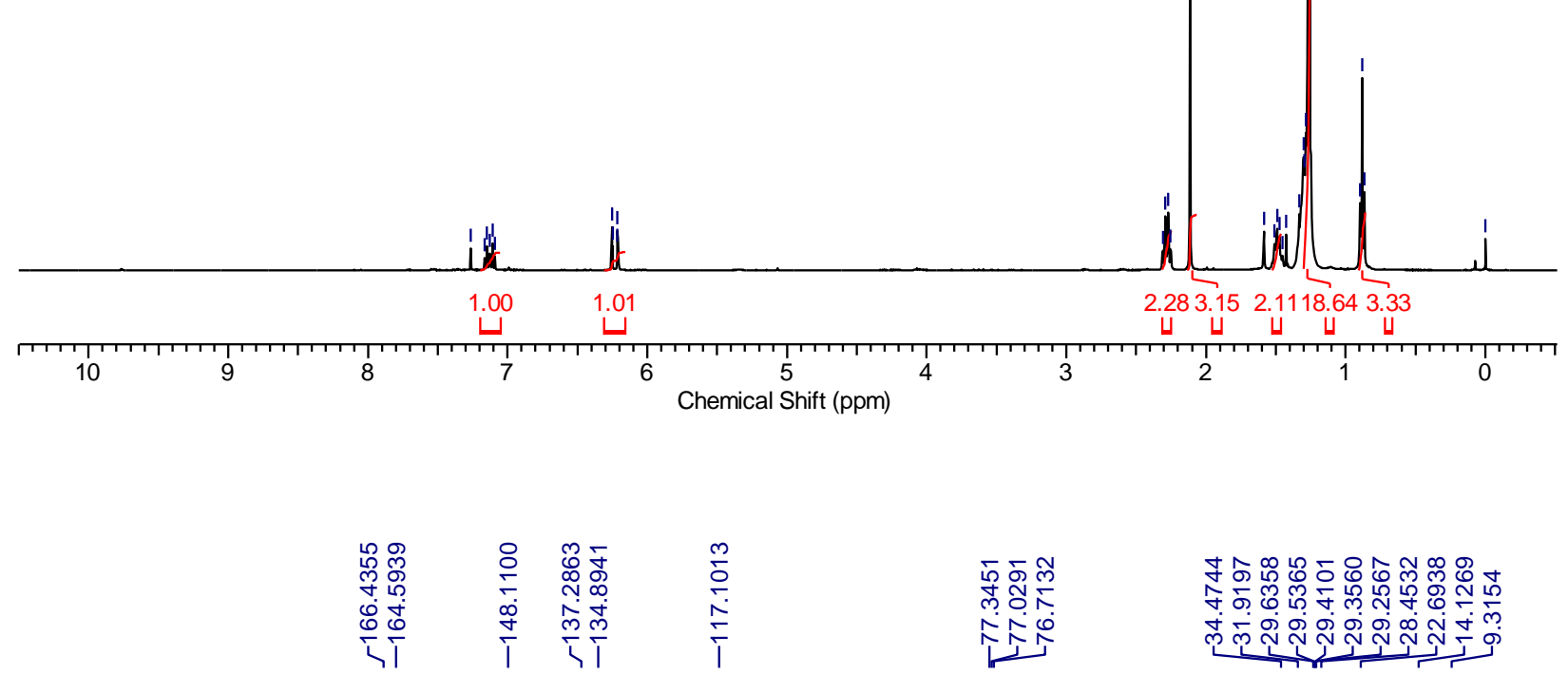

${ }^{13} \mathrm{C}\left\{{ }^{1} \mathrm{H}\right\}$ NMR (101 MHz) $\mathrm{CDCl}_{3}$

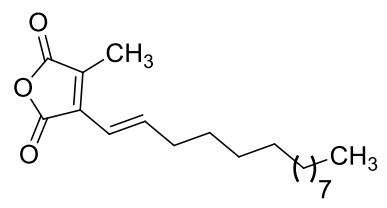

19

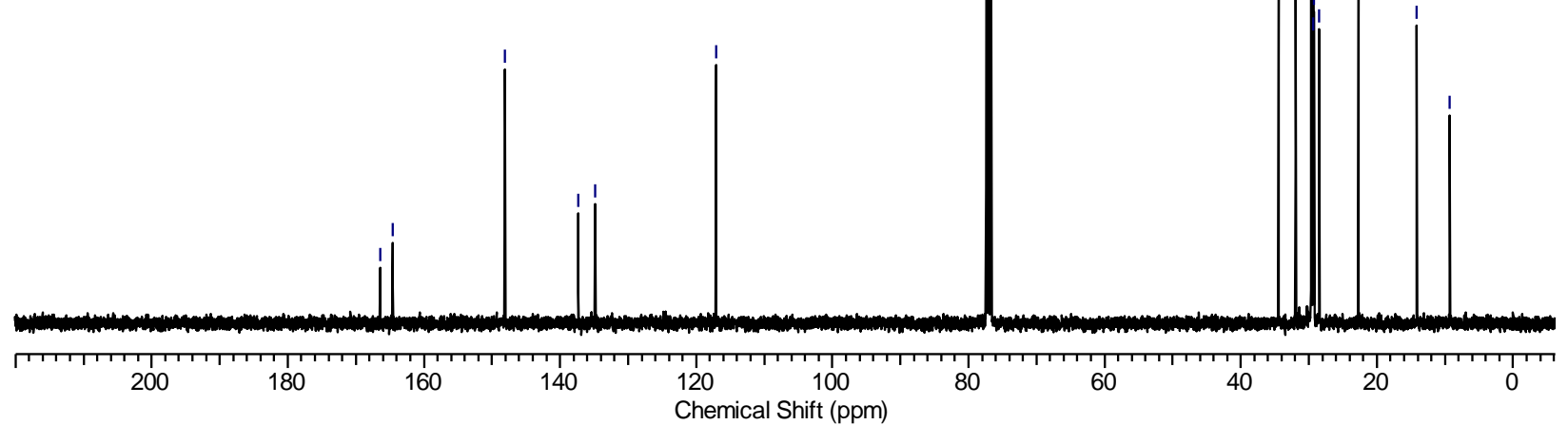


${ }^{1} \mathrm{H}$ NMR $(400 \mathrm{MHz}) \mathrm{CDCl}_{3}$
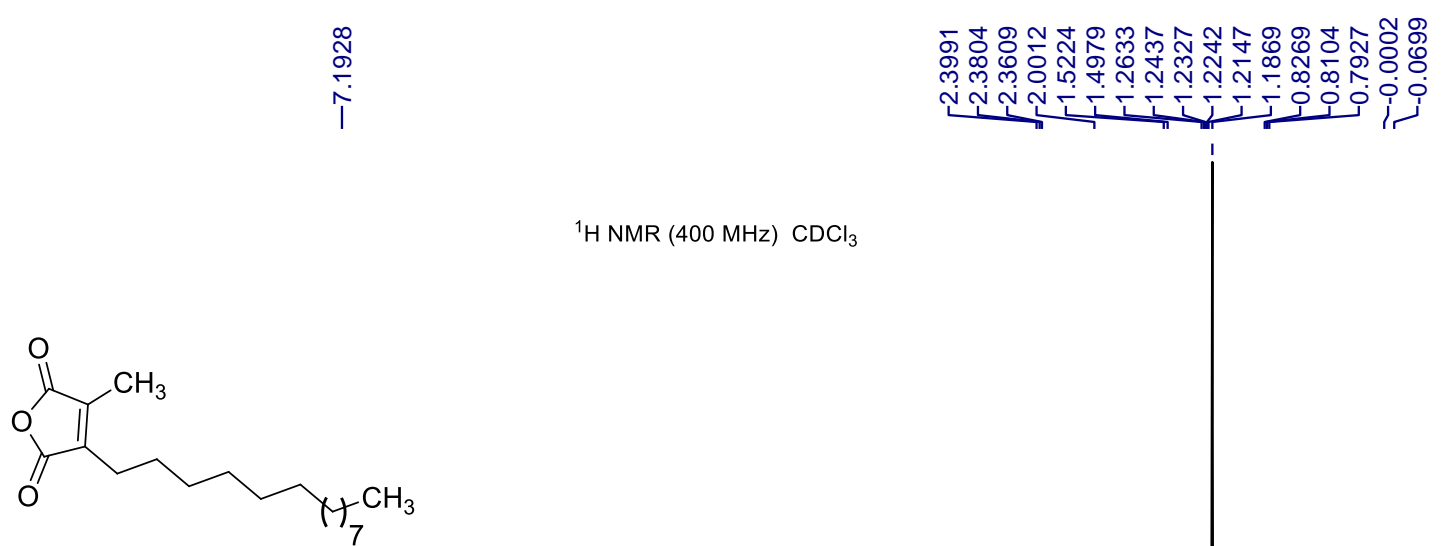

chaetomellic anhydride A (3)

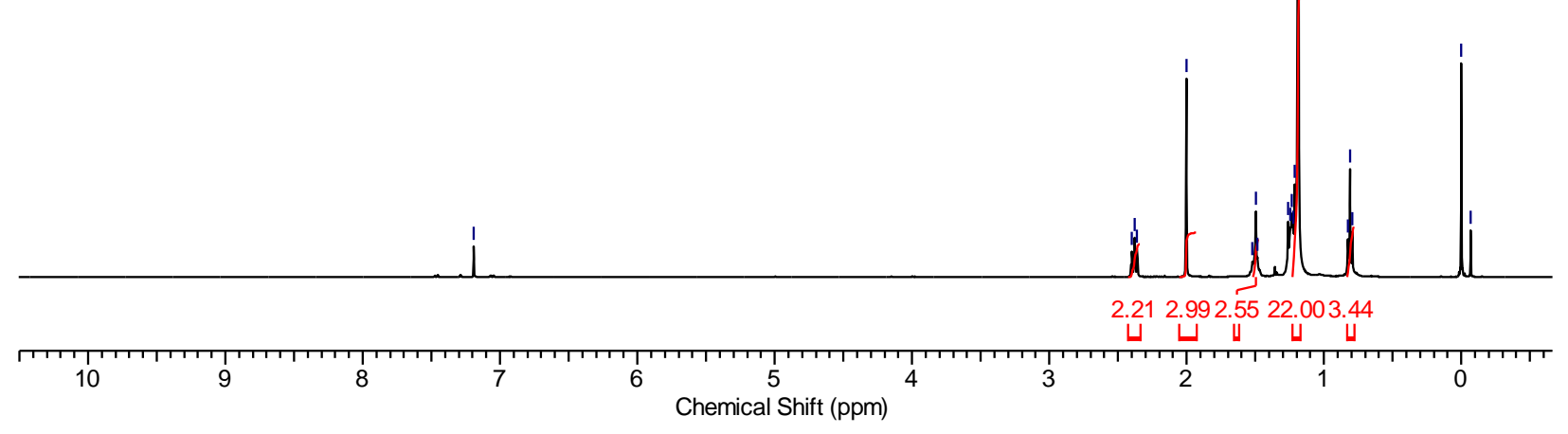

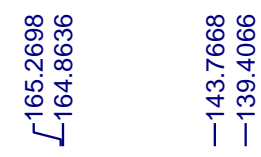

${ }^{13} \mathrm{C}\left\{{ }^{1} \mathrm{H}\right\}$ NMR (101 MHz) $\mathrm{CDCl}_{3}$

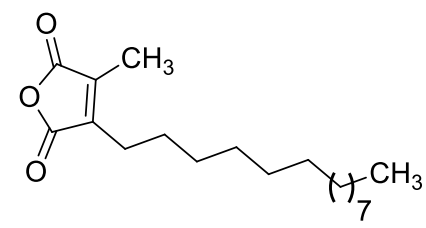

chaetomellic anhydride A (3)

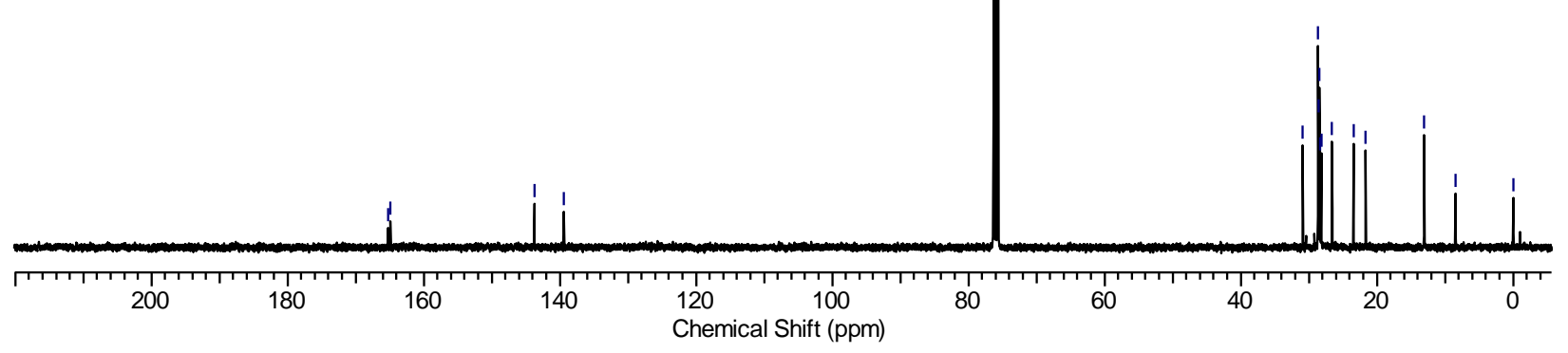




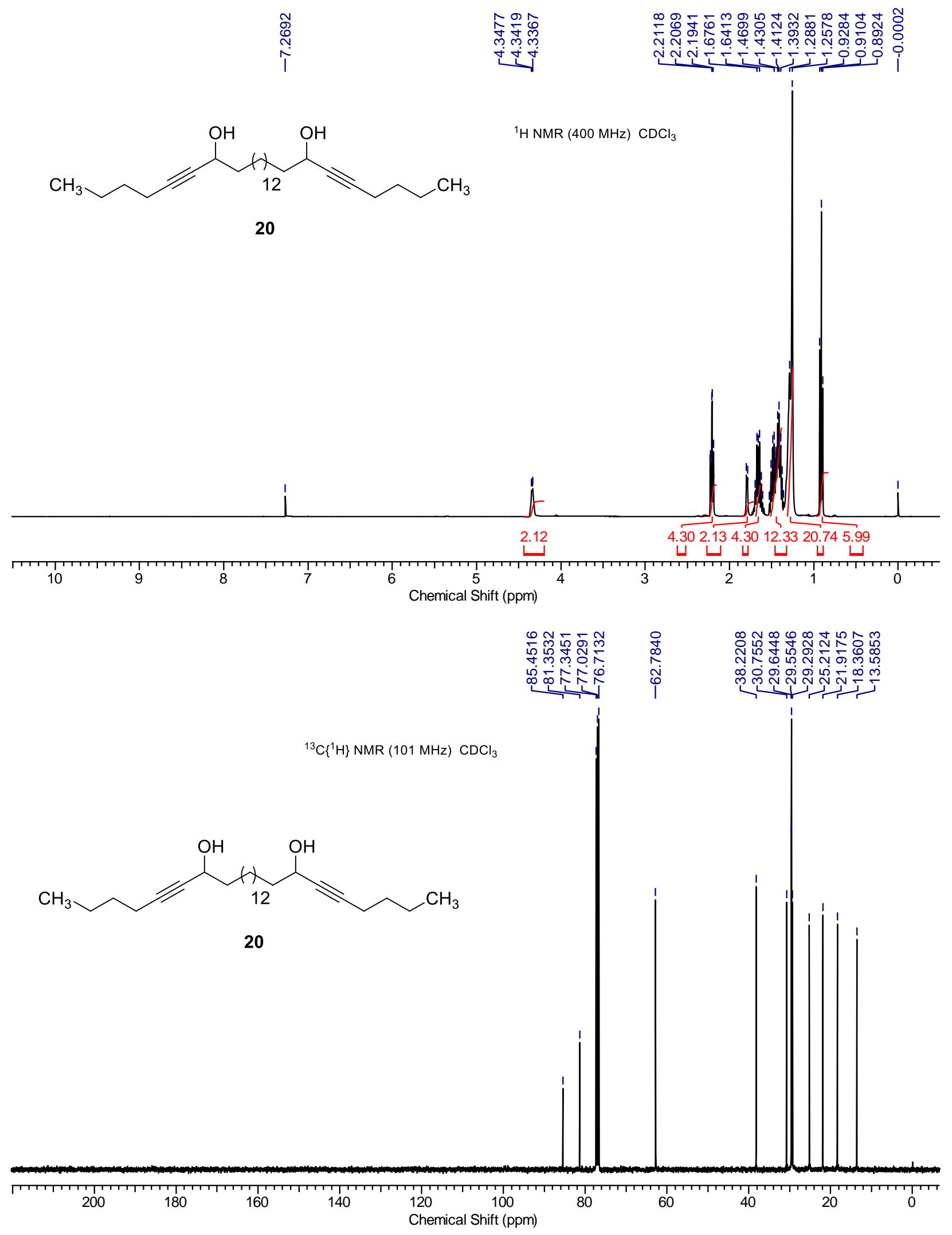




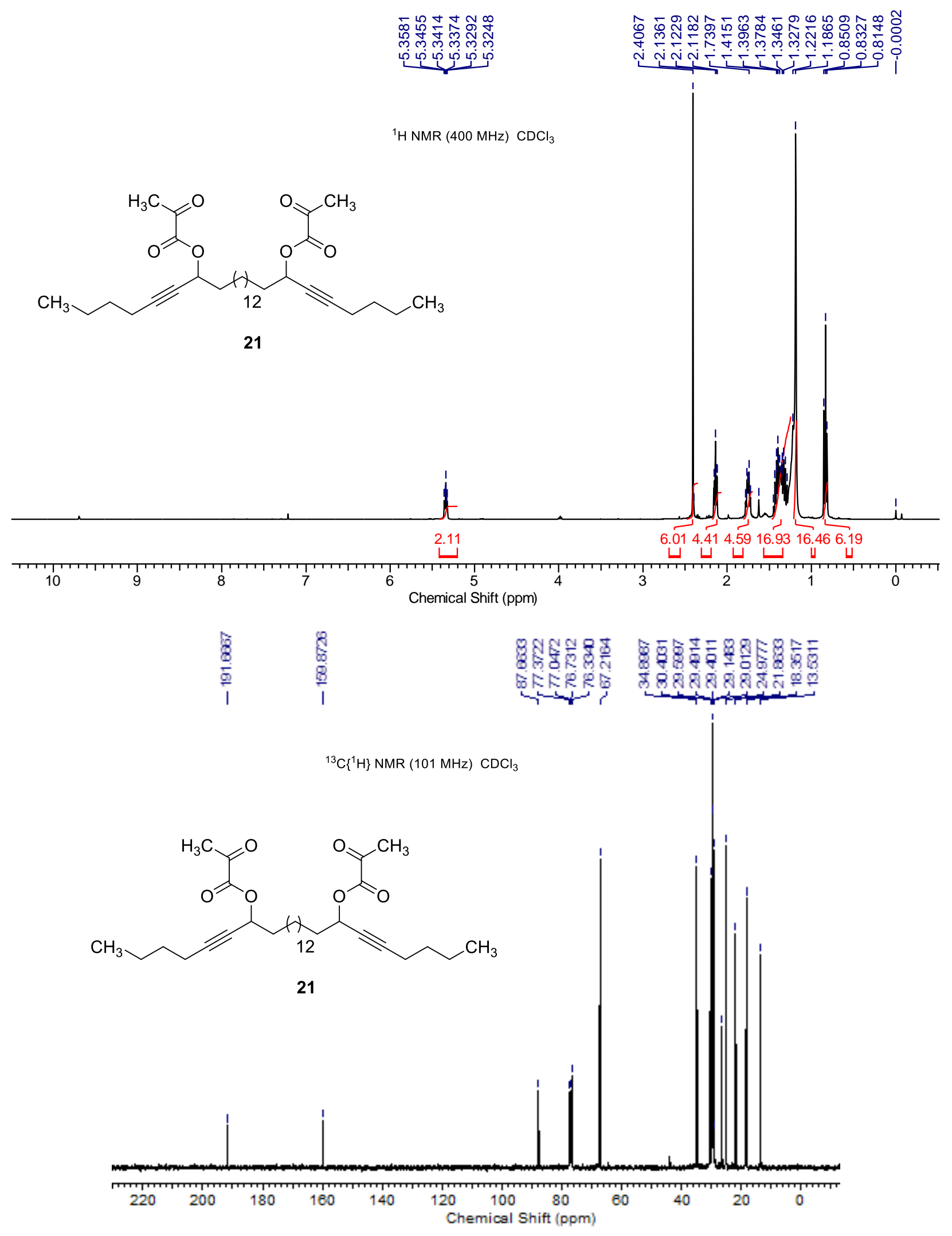




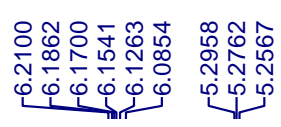

${ }^{1} \mathrm{H}$ NMR $(400 \mathrm{MHz}) \quad \mathrm{CD}_{2} \mathrm{Cl}_{2}$

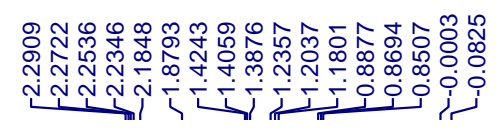

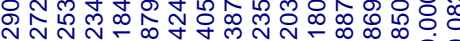
NNNNNTLT

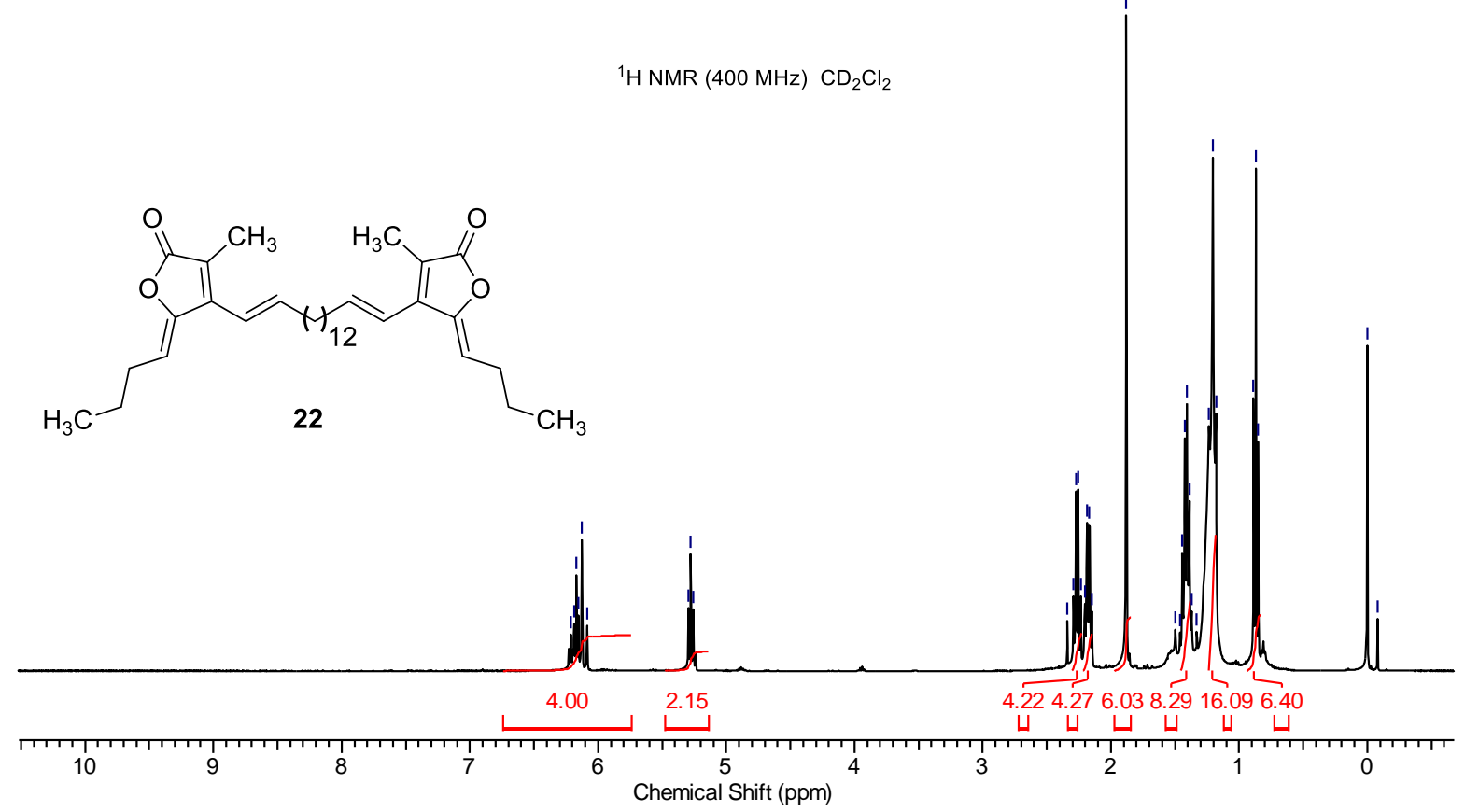
.

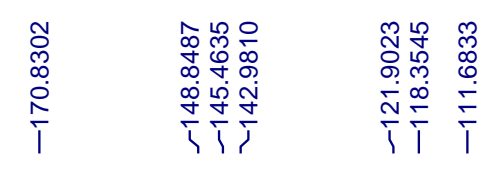

${ }^{13} \mathrm{C}\left\{{ }^{1} \mathrm{H}\right\}$ NMR (101 MHz) $\mathrm{CD}_{2} \mathrm{Cl}_{2}$<smiles>CCC/C=C1\OC(=O)C(C)=C1/C=C/[Y10](=O)/C=C/C1=C(C)C(=O)O/C1=C\CCC</smiles>

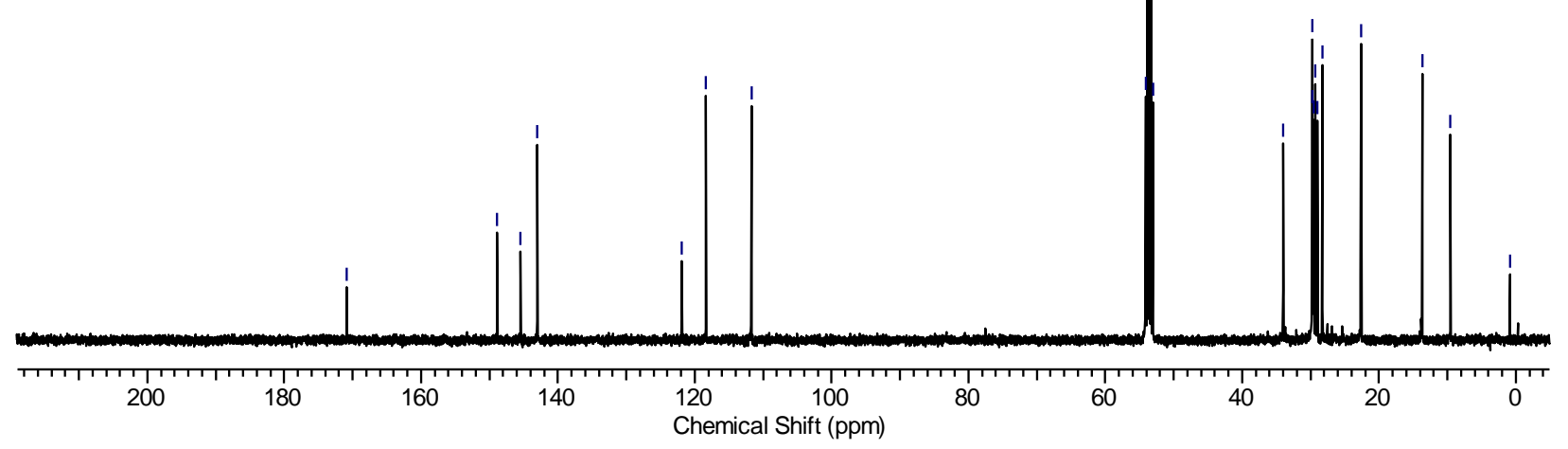




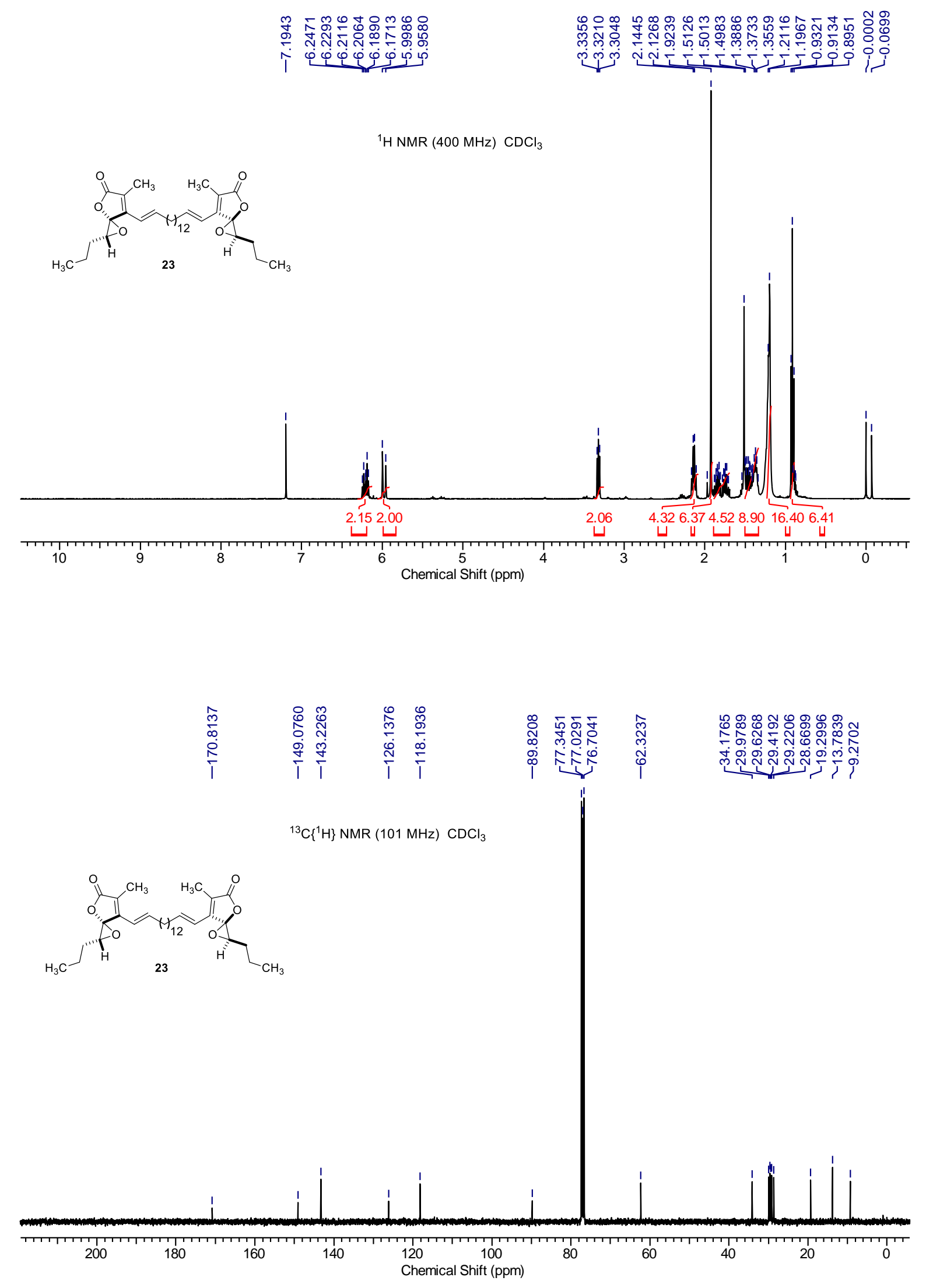


${ }^{1} \mathrm{H}$ NMR $(400 \mathrm{MHz}) \mathrm{CDCl}_{3}$<smiles>[H][Y10](/C=C/C1=C(C)C(=O)OC1=O)=C\C1=C(C)C(=O)OC1=O</smiles>

24

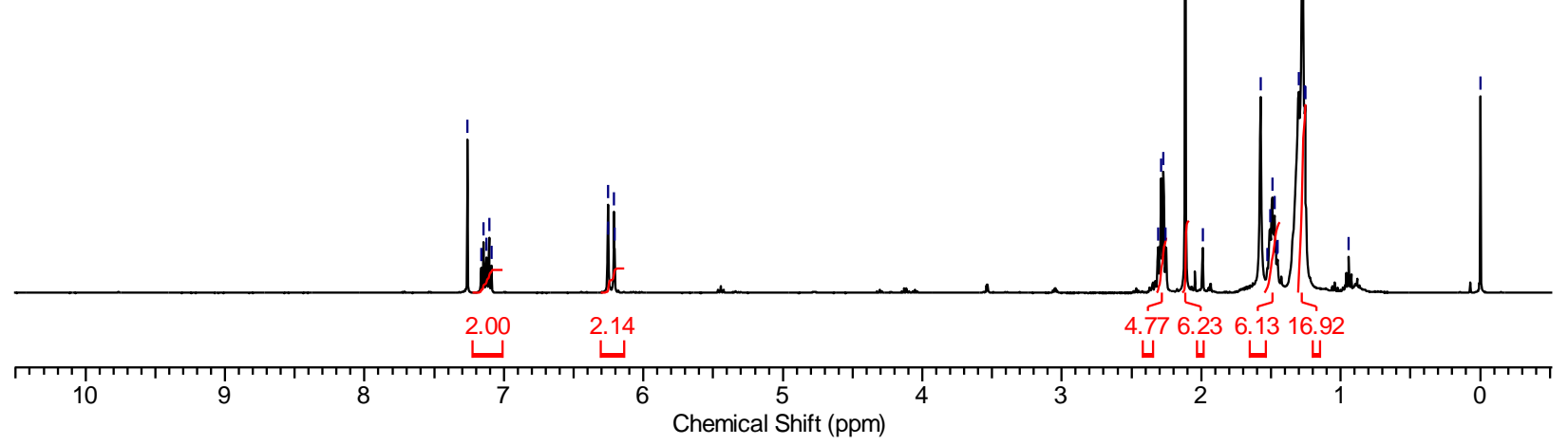

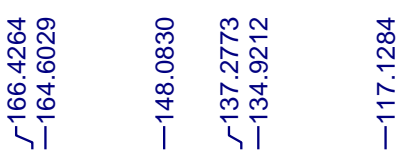

${ }^{13} \mathrm{C}\left\{{ }^{1} \mathrm{H}\right\}$ NMR $(101 \mathrm{MHz}) \mathrm{CDCl}_{3}$<smiles>[H][Y10](/C=C/C1=C(C)C(=O)OC1=O)=C\C1=C(C)C(=O)OC1=O</smiles>

24

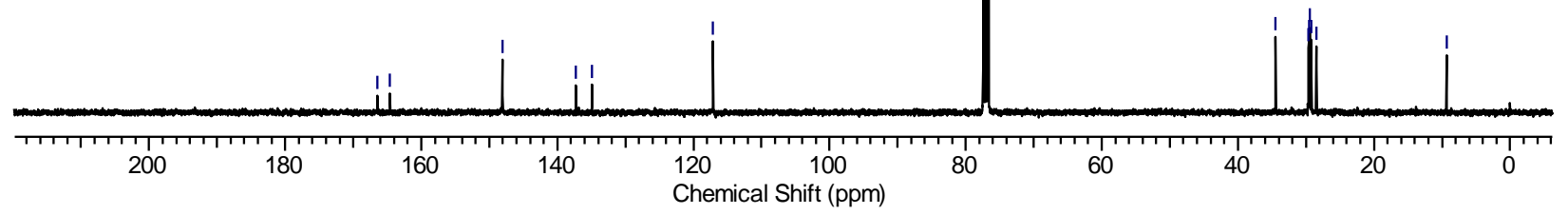




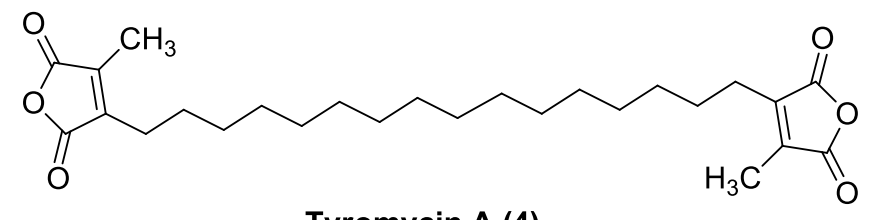

Tyromycin A (4)

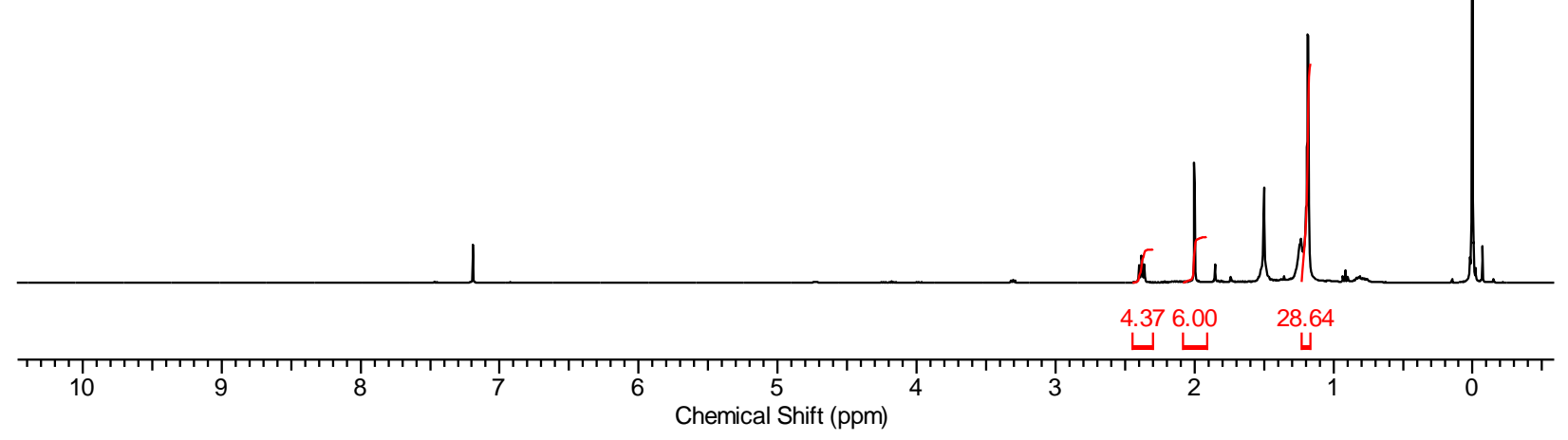

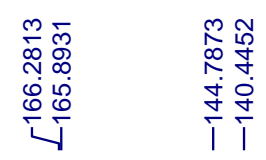

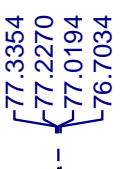

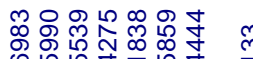

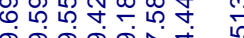

$\left.{ }^{13} \mathrm{C}^{1}{ }^{1} \mathrm{H}\right\} \mathrm{NMR}(101 \mathrm{MHz}) \mathrm{CDCl}_{3}$<smiles>CC1=C(CCCCCCCCCCCCCCCCC2=C(C)C(=O)OC2=O)C(=O)OC1=O</smiles>

Tyromycin A (4)

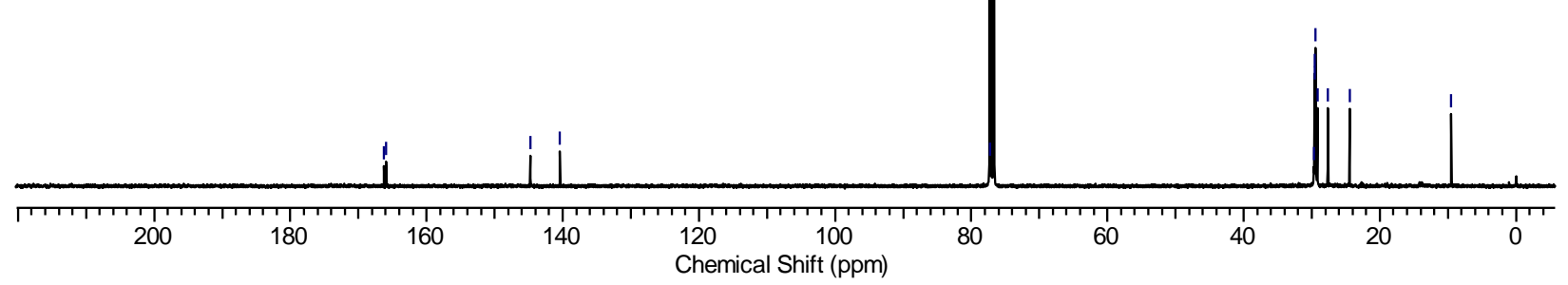


2. NOESY spectra of compound 18
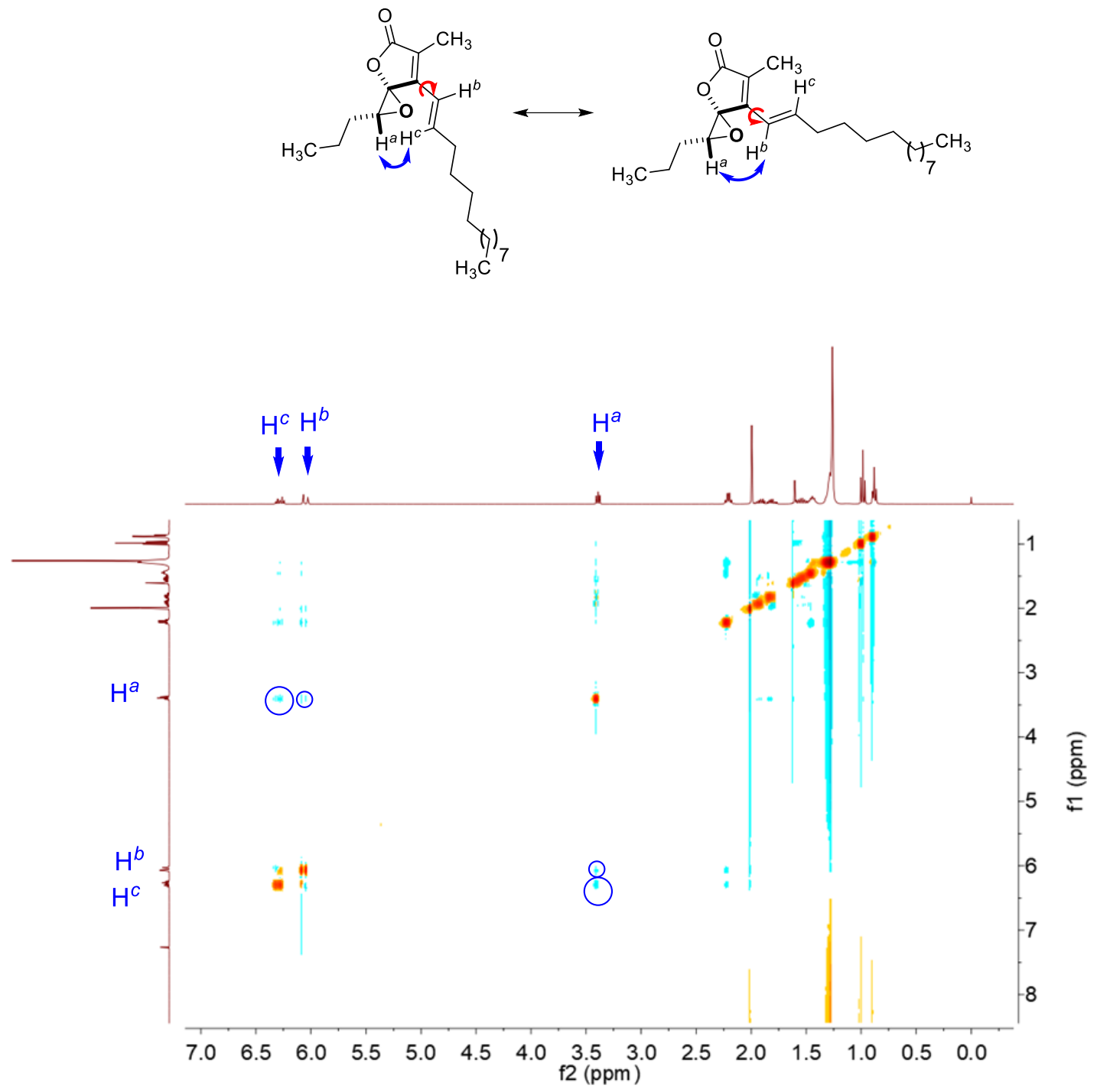